\title{
What Do We Mean by “Accessibility Research"?
}

A Literature Survey of Accessibility Papers in CHI and ASSETS from 1994 to 2019

\section{KELLY MACK}

University of Washington, Seattle, Washington, United States, kmack3@uw.edu

\section{EMMA MCDONNELL}

University of Washington, Seattle, Washington, United States, ejm249@uw.edu

DHRUV JAIN

University of Washington, Seattle, Washington, United States, djain@uw.edu

\section{LUCY LU WANG}

Allen Institute for AI, Seattle, Washington, United States, lucyw@allenai.org

JON E. FROEHLICH

University of Washington, Seattle, Washington, United States, jonf@cs.uw.edu

\section{LEAH FINDLATER}

University of Washington, Seattle, Washington, United States, leahkf@uw.edu

Accessibility research has grown substantially in the past few decades, yet there has been no literature review of the field. To understand current and historical trends, we created and analyzed a dataset of accessibility papers appearing at CHI and ASSETS since ASSETS' founding in 1994. We qualitatively coded areas of focus and methodological decisions for the past 10 years (20102019, $N=506$ papers), and analyzed paper counts and keywords over the full 26 years ( $N=836$ papers). Our findings highlight areas that have received disproportionate attention and those that are underserved-for example, over 43\% of papers in the past 10 years are on accessibility for blind and low vision people. We also capture common study characteristics, such as the roles of disabled and nondisabled participants as well as sample sizes (e.g., a median of 13 for participant groups with disabilities and older adults). We close by critically reflecting on gaps in the literature and offering guidance for future work in the field.

CCS CONCEPTS $\bullet$ Human-centered computing Accessibility Accessibility theory, concepts and paradigms $\bullet$ Social and professional topics $\sim$ User characteristics $\sim$ People with disabilities

Additional Keywords and Phrases: Accessibility, assistive technology, disability, literature review

\section{Please cite this work as:}

Kelly Mack, Emma McDonnell, Dhruv Jain, Lucy Lu Wang, Jon E. Froehlich, and Leah Findlater. 2021. What Do We Mean by "Accessibility Research"?: A Literature Survey of Accessibility Papers in CHI and ASSETS from 1994 to 2019. Proceedings of the 2021 CHI Conference on Human Factors in Computing Systems. Association for Computing Machinery, New York, NY, USA. DOI:https://dl.acm.org/doi/10.1145/3411764.3445412 


\section{INTRODUCTION}

The ACM Conference on Accessible Computing (ASSETS) was founded in 1994 to study the accessibility of digital technologies and to innovate new solutions to real-world accessibility problems. Over the almost three intervening decades, computing has evolved from desktop computers to include mobile touchscreen devices, augmented and virtual reality, and the Internet of Things-all of which pose both technological promise as well as challenges for people with disabilities. While originally a niche topic, accessibility has become a critical focus of industry and the HCI research community as a whole. Indeed, "accessibility" was the second-most popular keyword at ACM CHI 2019 [170].

As the accessibility field matures, surveying its current state and historical context allows us to identify research gaps, discover and question norms with the help of empirical evidence, and provide an entry point for newcomers to understand the field. While focused literature reviews have examined specific subsets of accessibility research (e.g., autism [140,156], visual impairment $[19,29]$ ), no broader survey exists. In this paper, we review accessibility research appearing at the two most popular venues for accessible computing-the ACM CHI and ASSETS conferences-from 1994 (the inception of ASSETS) to 2019. Our key research questions include: Who does accessibility research focus on? What are the stated goals, such as increasing digital accessibility or increasing independence for people with disabilities and older adults? What research methods are used, including study design decisions such as sample size, study location, and whether participatory methods are used? And, finally, how has accessibility research evolved over time?

To answer these questions, we created a dataset of 836 accessibility papers appearing at CHI and ASSETS from 1994-2019, manually coding 506 of those papers from a recent 10-year period (2010-2019) and analyzing temporal trends in paper counts and keywords for the full dataset. The manual coding captures research foci (i.e., communities of focus, issues addressed, contribution types), methodological decisions (e.g., study methods, sample sizes), and the roles of both disabled and nondisabled participants in accessibility studies. Findings show, for example, that accessibility research focuses disproportionately on the needs of blind and low vision (BLV) users, employs a median sample size of 13 for disabled and older adult participant groups, and commonly pairs some research issues with specific communities of focus (e.g., supporting communication for $\mathrm{d} /$ Deaf and hard of hearing people but personal informatics and behavior change for autism-focused work). Complementing these findings, paper counts and keyword frequencies in the full 26 years of the dataset demonstrate that accessibility research is increasing, even outpacing the growth of $\mathrm{CHI}$ in the past decade. While there has been an expansion in what user communities receive attention from accessibility researchers, the popularity of BLV work is long-standing. Our data allows us to deeply reflect on the accessibility community and its norms as created and preserved by authors and reviewers.

In summary, this paper contributes: (1) a characterization of current trends in accessibility research, including identification of areas that have received disproportionate attention, areas that are underserved, and patterns in how both disabled and nondisabled participants are included in the research; (2) complementary temporal patterns from 1994-2019, particularly in terms of paper counts and communities studied; (3) reflections and recommendations to guide future accessibility research, identifying opportunities for growth and methodological decisions to question; (4) an open-source dataset of 506 accessibility papers from CHI and ASSETS with our applied 
qualitative codes and the metadata of 836 accessibility papers from the same venues since 19941, enabling future meta-analyses by the HCI accessibility community.

\section{BACKGROUND AND RELATED WORK}

Reflecting on the field of accessibility requires a historical understanding of societal, cultural, and political developments. While many countries have disability rights legislation-including international treaties such as the United Nations Convention on the Rights of Persons with Disabilities (CRPD), which stipulates equal access to information and communication technologies, including the Internet [87]-we focus specifically on US policy, which helped influence early CHI and ASSETS accessibility research [50,84]; see Lazar et al. [88] for a broader policy overview. Below, we provide background on the history of accessibility research as well as current trends.

\subsection{The History of Accessibility Research}

Throughout history, disability has been cast as a medical problem-a defect that must be cured, rehabilitated, or eliminated if a person is to achieve full capacity as a human [136]. The medicalization of disability began to draw ardent criticism in the 1960s through the emerging disability rights movement [38,134], when activists began framing disability "as a socially and culturally constructed form of societal oppression" [38]. This redefinitionultimately termed the "social model" - shifts the focus of disability from the individual to society and, crucially, distinguishes between impairment as a biological or physical condition and disability as a social and environmental construction [44]. Clarifying this distinction, Kasnitz et al. [76] state that "disability exists when people experience discrimination on the basis of perceived functional limitations". The disability studies community continues to debate and build on the social model, such as Kafer's [71] political/relational model, which serves as a "friendly departure" and seeks to better encompass the lived experience of impairments, such as pain or chronic illness, and to identify the deeply politicized nature of disability.

The social model and the disability rights movement helped catalyze a new socio-political agenda [133]. In 1973, the US Rehabilitation Act was passed, stating that: "no otherwise qualified individual with a disability [shall be excluded] from the participation in, be denied the benefits of, or be subjected to discrimination [under any program receiving federal assistance]" (29 U.S.C. 794d. Section 504. 1973). In a 1986 amendment, the Act was expanded to "develop and establish guidelines for electronic equipment accessibility" (Section 508). Although lacking specifics, including definitions of "accessibility" and how guidelines would be enforced, Section 508 was a milestone for accessible technology. Highlighting its importance to the CHI community, early accessibility pioneers Richard Ladner and Gregg Vanderheiden, held a "Section 508” panel at CHI'88 to discuss the development of accessibility guidelines and implications for HCI [84].

In 1990, the Americans with Disabilities Act (ADA) was passed, which, critically, recognized the minority status of Americans with disabilities, extending protections beyond the government sector and requiring places of "public accommodation" to provide people with disabilities appropriate aids or services [38]. Although the ADA has been inconsistently applied to computing technology [86], a 2019 US Supreme Court decision [36] signals increasing acceptance of its applicability. Shortly after the ADA's passage, the Communications of the ACM dedicated an issue to disability and computing [10], highlighting "research related to computers and people with disabilities as a valid area of scientific endeavor" and arguing that "design for disability" was important, cost-effective, and broadly

\footnotetext{
1 The dataset, codebook, and analysis scripts are available at the following link: https://github.com/makeabilitylab/accessibility-literature-survey.
} 
beneficial [50]. The editors invited ACM members to join the "newly revitalized Special Interest Group on Computers and the Physically Handicapped (SIGCAPH)" and to attend the inaugural ASSETS conference, which took place in $1994 .^{2}$

Almost three decades later, accessibility has become a key area of CHI [170] and ASSETS is in its 22nd year. ${ }^{3} \mathrm{CHI}$ 2021's subcommittee on "Accessibility and Aging" defines its focus as: "technology design for or use by people with disabilities including sensory, motor, and cognitive impairments" and "for or use by people in the later stages of life" [4]. Likewise, the ASSETS 2020 conference advertises itself as the "premier forum for research on the design, evaluation, use, and education related to computing for people with disabilities and older adults" and describes relevant topics as including but not limited to: "new enabling technologies, studies of how technologies are used by people with disabilities, explorations of barriers to access, and evaluations of accessibility education methods" [3].

\subsection{Current Trends in Accessibility Research}

While no surveys exist of accessibility literature as a whole, researchers have examined sub-areas, including visual accessibility [20,28,52], autism [94,120,140], design with older adults [151], children with "special needs" generally [15], and design philosophies for accessible technology [121,158]. Bhowmick and Hazarika [20], for example, conducted a high-level analysis of 3,010 visual accessibility papers ${ }^{4}$ retrieved from four scientific databases, identifying CHI and ASSETS as the most common publication venues. In a more detailed examination of quantitative evaluation practices in technology development for people with visual impairments, Brulé et al. [28] analyzed 178 papers published at CHI, ASSETS, TOCHI, and TACCESS from 1988-2019. They found that web browsing was the most popular application area (24.2\% of papers), followed by education (14.6\%) and mobility (14.6\%). Most papers $(70.2 \%)$ included at least one quantitative empirical evaluation, with a more recent trend to incorporate formative studies. Our work extends similar analyses to the full accessibility literature at CHI and ASSETS, comparing trends across different user populations.

Other surveys have taken a critical discourse analysis approach [140,151]. Vines et al. [151] analyzed 644 papers focusing on aging published between 2007 and 2012 across 16 HCI venues. They identify four discourses common in $\mathrm{HCI}$-health economics, socialization (e.g., social isolation), homogeneity (i.e., generalization across older adults), and deficits (i.e., declining abilities) — and call on HCI researchers to avoid the biomedicalization of older adults and to consider the diversity of this population. This deficit discourse is particularly relevant to accessibility research, as also argued by Knowles et al. [79], who state that conflating aging with accessibility "perpetuates negative stereotypes of aging and promotes ageism." Cognizant of this issue, we only include aging-related papers in our dataset if the authors identified the paper using one of our accessibility-related search terms (Section 3). Another example of a critical discourse analysis comes from Spiel et al. [140], who reviewed 185 papers on technologies for autistic children. They focused on the purpose of the technologies and issues of power dynamics, identifying six focus areas such as behavior analysis and social skills. They conclude with the critique that there is "a predominant focus on corrective, othering approaches" that "embody and negotiate [...] neurotypical expectations." We complement and extend these conclusions with quantitative analysis of papers focusing on autism regardless of participant age.

\footnotetext{
${ }^{2}$ ASSETS was initially called the "ACM Conference on Assistive Technologies" and later renamed the "ACM SIGACCESS Conference on Computers and Accessibility". SIGCAPH was renamed SIGACCESS (Special Interest Group on Accessible Computing) in 2003.

${ }^{3}$ ASSETS occurred every other year from 1994 to 2004 and every year since, so ASSETS 2020 marks the $21^{\text {st }}$ ASSETS offering.

${ }^{4}$ It appears that their corpus included extended abstracts like posters in addition to full papers.
} 
Finally, although not literature surveys, accessibility researchers have offered a growing number of critical reflections, calling for greater inclusion of disability studies within accessibility research and for empowering disabled scholars [141]. In an early landmark paper, Mankoff et al. [99] called for accessibility researchers to adopt disability studies learnings and to increase representation of disabled people in accessibility work. They cautioned that the medical model, which "designers of assistive technologies may find [...] pragmatically useful" overemphasizes "fixing" the individual rather than addressing larger-scale societal issues related to access and oppression. Frauenberger [44] introduced a "critical realist perspective" to assistive technology design, incorporating both intrinsic (i.e., individual) and extrinsic (i.e., structural) factors. Since then, the integration of critical disability studies perspectives to accessibility has only strengthened, with papers examining issues of ableism and epistemic violence in accessibility research [164], the need for greater representation of disabled people in the community [141,155], the conflation of aging and disability [79,151], and interdependence as a guiding value of assistive technology [16]. Our survey method touches on issues of representation by analyzing the use of proxies and of participatory and codesign methods, as well as quantifying who is included as participants in accessibility research.

\section{METHOD}

To understand the current state of accessibility research and reflect on changes over the past three decades, we performed a literature survey of the ACM CHI and ASSETS conferences-two of the most popular venues for accessibility research. This review includes a qualitative analysis of a recent 10-year period $(2010-2019, N=506$ papers) and a briefer quantitative analysis of the 26-year period dating back to the first year of ASSETS (1994-2019, $N=836)$.

\subsection{Dataset Creation}

We created the dataset in two phases, focusing first on the 2010-2019 period then expanding to the full 26 years. The final dataset includes only short and long technical papers at ASSETS and CHI (e.g., no posters, keynotes, etc.).

\subsubsection{A Recent 10-year Period: 2010-2019}

To identify accessibility papers from 2010-2019, we queried the ACM Digital Library (DL) between October and December 2019. Because ASSETS is the SIGACCESS Conference on Accessible Computing, we considered all ASSETS papers to be, by definition, about accessibility. CHI papers, however, needed to be filtered to only those that were accessibility-focused, which was complicated by intersections with other sub-disciplines of HCI, particularly research with older adults, health, rehabilitation, and education. Not all papers at these intersections take an accessibility framing, whether explicitly or implicitly. For example, in studying ridesharing with older adults, Meurer et al. [105] explicitly distance their work from a deficit or disability discourse (see [151]), while in another study, Harrington et al. [54] focus on older adults and health but do not discuss technology accessibility or disability. Thus, so as not to misattribute accessibility or disability framings to these and similar papers, we only considered papers where the authors used one of the following common accessibility terms in the title, abstract, or author keywords: disab-(e.g., disability, disabled), access-(e.g., accessibility, accessible), impair-(e.g., impairment, impaired), and assistive technolog- (e.g., technology, technologies). ${ }^{5}$ We did not use full text search on the CHI proceedings

${ }^{5}$ Specifically, our six search terms were accessibility, disability, disabled, impairment, impaired, or assistive technology, but since the ACM DL search functionality stemmed on keywords, it also provided all results matching the same roots (e.g., access, accessible). Since running our queries, the ACM DL underwent major revisions which may have changed search logic. Therefore, these queries may not be reproducible. 
because our early investigation showed that it resulted in substantially more false positives. We also considered including more disability-specific keywords (e.g., blind, deaf), but did not do so because we were concerned that the results would be biased toward those disability types at the expense of emergent areas that we had not predicted.

Our initial search retrieved all 291 technical papers (short or long) that appeared in the ASSETS proceedings from 2010-2019 and identified 594 candidate CHI papers from that time period. ${ }^{6}$ The candidate CHI papers still included many false positives (enhanced by stemming), such as referring to "access" in the context of security research or a "disabled" user interface feature. Thus, two research team members each independently coded disjoint halves of the candidate papers, marking each one as relevant, irrelevant, or needs discussion. In total, 203 were marked as relevant, 49 as needs discussion, and 342 as irrelevant. The researchers then reviewed each other's irrelevant codes, disagreeing in 4 of the 342 instances (1.0\%). These disagreements and all needs discussion papers were resolved through consensus between the two coders and for a small set $(N=9)$, with the entire research team. An additional four relevant papers were later classified as irrelevant during the more thorough qualitative coding, resulting in 215 relevant CHI papers. Combined with the 291 ASSETS papers, the 2010-2019 dataset thus contains 506 papers.

Finally, because our approach may have missed some accessibility papers at CHI, we performed a false negative check. We randomly selected 100 of the 4,927 CHI papers that were not among our candidates, and two coders independently reviewed them. Only one paper was arguably an accessibility paper: [125] focused on designing for older adults with memory impairment, but only used our keywords in the full text and not in the metadata fields.

\subsubsection{Expanding to the Full 26 Years: $1994-2019$}

We subsequently built on the 506 papers above by adding all 285 ASSETS papers and 45 CHI accessibility papers that appeared in 1994-2009, for a total of 836 papers over the 26-year period. For this expansion, we acquired a metadata file directly from the ACM that included CHI and ASSETS proceedings through January 2020, with each publication's title, authors, author keywords, venue, publication year, DOI number, and abstract. The ACM also separately provided a list of the official paper counts per conference per year, with the exception of the first four years of ASSETS. However, we encountered several issues with data quality. First, the aggregate counts of papers from the metadata file did not always match the expected counts per year from their official list. Thus, one author manually reviewed the ASSETS and CHI proceedings frontmatter and/or conference website content (if available) in the full time period (1994-2019), fixing discrepancies between the ACM's official reporting of paper counts and the actual paper counts (e.g., the ACM count erroneously missed short papers for CHI 2008) and removing any papers from the dataset that were not short or long technical papers (e.g., early CHI design briefs). This manual review resulted in a list of 7,209 $\mathrm{CHI}$ and ASSETS papers, which was off from what we expected by only six papers (i.e., a $0.1 \%$ discrepancy). Second, some of the paper entries had malformed abstracts or missing keywords. We programmatically fixed 271 of the missing abstracts by extracting them from full-text metadata fields, leaving 98 papers (1.4\%) without abstracts, and manually retrieved or confirmed the absence of keywords for 131 papers, leaving 9 papers $(0.1 \%)$ without keyword information. ${ }^{7}$

\footnotetext{
${ }^{6}$ Advanced querying for strings in the title field in ACM DL searches for the string in both the official title and the subtitle.

${ }^{7}$ In our final dataset, $8 \mathrm{CHI}$ and 18 ASSETS papers did not have author keywords, which we verified by looking at the paper PDF. We were unable to gain access to the PDF of 9 ASSETS papers published in the proceedings of the 1994 conference, and their keyword information remains unknown.
} 
We then identified candidate papers from CHI 1994-2009 by string matching on the following terms in the title, subtitle (separate from title in the ACM metadata), abstract, and author keywords: accessibility, assistive tech-, disab-, and impair-. This string matching implicitly allowed for some stemming (e.g., disab matches to disability and disabled), but was stricter than the ACM DL search stemming we had used in Section 3.1.1. The result was 74 candidate CHI papers. The same two researchers as in Section 3.1.1 independently checked these candidates to eliminate false positives: three disagreements arose $(4.1 \%)$ and seven papers (9.5\%) were marked as needs discussion - all were resolved through consensus. Ultimately, 45 relevant CHI papers remained, which resulted in a 26-year accessibility dataset with 836 papers in total: 260 from CHI and 576 from ASSETS.

Finally, to validate this string-matching method used on the 1994-2009 dataset, we applied it to the 2010-2019 CHI papers. The search identified 355 candidate CHI papers, including all 215 that we had manually deemed relevant (see 3.1.1), plus 140 false positives that we had eliminated. We again also checked for false negatives in the 1994-2009 data by randomly selecting 100 papers from CHI 1994-2009, finding that two of them did not use our keywords but could arguably appear at ASSETS [9,130]. Thus, we acknowledge that a small set of papers may not be included in our dataset, which was a tradeoff we considered necessary to eliminate false positives.

\subsection{Analysis}

We qualitatively coded the 506 papers from 2010-2019, and programmatically analyzed all 26 years of data $(\mathrm{N}=836)$. We note that the process of creating and analyzing the dataset involved subjective judgments, and that this research was conducted by white and Asian scholars, two of whom identify as disabled. Authors ranged from first year graduate students to professors who have been publishing accessibility research in CHI and ASSETS for about 15 years. We come to this analysis with deep personal and academic commitments to accessibility and acknowledge that our scholarship reflects our own biases and beliefs.

\subsubsection{Qualitative Coding of a 10-year Snapshot}

To analyze the 506 papers from 2010-2019, we used an iterative process to develop and apply a codebook. The initial codebook included deductive codes based on our research questions, such as user communities of focus, technologies, and study methods. Three authors then went through three iterations of independently applying and updating the codebook, using a randomly selected set of 25 papers for each iteration. After each set, the coders came together to compute interrater reliability (IRR) using Krippendorff's alpha [169], refine or eliminate existing codes, add new inductive codes, manually resolve disagreements through consensus, and discuss the outcome with the full research team. The final codebook included 10 overarching categories with 2-10 subcodes each. Excluding "Other" subcodes, IRR across subcodes ranged from .63 to .91 and was on average $0.76(S D=.09)^{8}$. Finally, the remaining papers were split into approximately three sets and coded separately by the same three coders who developed the codebook. Halfway through their sets, all three authors coded an overlapping set of five papers to provide an opportunity for discussing any emergent concerns; disagreements on this small set were resolved through consensus.

The final codebook is summarized in Table 1. While full code definitions can be found in the Supplementary Materials, we offer a few notes here. Community of focus is the accessibility-related population or community being studied or positioned by the authors as benefiting from the research. For Participatory design use, we coded "yes" if

${ }^{8}$ We did this IRR exercise as we were establishing our final dataset. As such, in our second and third round of coding, we coded one paper in each round that did not qualify for the final dataset (two ASSETS experience reports). 
a paper explicitly stated that they used "codesign", "co-design", or "participatory design" in their study method; there were a few papers that used phrases like "participatory approach", which we coded as "no" (e.g., [49,98]). Use of proxies refers to when someone other than the target user is asked to speak to the thoughts, preferences, or behaviors of a person with a disability in place of that person themselves [7,112], which is distinct from participants who were acting in strictly a stakeholder or caregiver role. Issue addressed examined the research goal of each paper, while Contribution type identified the paper's research contribution(s) according to Wobbrock and Kientz's Research Contributions in Human-Computer Interaction [159]. Finally, Participant count captured the number of participants in each participant group in the user study or studies in the paper. For these counts, we grouped participants into one of 12 categories covering the Participant groups codes, but also more specifically breaking down people with disabilities into one of the Communities of focus codes. We additionally extracted papers about crowdworkers from the "other" code, since their sample sizes were considerably larger from the other papers coded as "other".

\subsubsection{Programmatic Analysis of 26-year Temporal Trends}

To complement the qualitative coding, we programmatically examined paper counts and keyword frequencies over the full 26-year period ( $N=836$ papers). For keyword analysis, two researchers manually reviewed all of the 2,101 unique author keywords appearing at least twice in the dataset ( $N=511$ keywords), categorizing each one as being thematically related to users (i.e., community of focus), technology, method, or none of the above. Then, within each of these three themes (user, technology, and method), the researchers grouped highly similar keywords into higher-level categories informed by our qualitative codebook; for example, the user-related keywords of "mobility", "motor disabilities" and "motor impairments" were combined into a "motor/physical" category. Because author keywords tended to be sparse, we then enriched the keyword data by searching for additional occurrences of all 2,101 author keywords in paper titles and abstracts, looking for exact token matches. This enrichment process allowed us to identify user, technology, and method keywords for an additional 202, 203, and 398 papers, respectively. However, ultimately, 125 papers (15.0\%) had no user keywords, 108 papers (12.9\%) had no technology keywords, and 285 papers (34.1\%) had no method keywords.

Table 1: The final codebook with 10 code categories and 52 subcodes; the average IRR is computed across the subcodes for each code. When applicable, the IRR calculations do not include the code of "other". Multiple refers to "multiple codes can apply."

\begin{tabular}{|c|c|c|c|}
\hline Category & Codes & Mean IRR & Multiple? \\
\hline Community of focus & $\begin{array}{l}\text { Blind or low-vision (BLV); deaf or hard of hearing (DHH); autism; } \\
\text { intellectual or developmental disability (IDD); motor or physical } \\
\text { impairment; cognitive impairment; older adult; general disability or } \\
\text { accessibility; other }\end{array}$ & $\begin{array}{c}0.91 \\
(S D=0.17)\end{array}$ & Yes \\
\hline Study method & $\begin{array}{l}\text { Controlled experiment; interview; survey; usability testing; case study; } \\
\text { focus group; field study; workshop or design session(s); other }\end{array}$ & $\begin{array}{c}0.75 \\
(S D=0.32)\end{array}$ & Yes \\
\hline Participatory design use & Yes; no & $\begin{array}{c}0.74 \\
(S D=0.00)\end{array}$ & No \\
\hline User study location & $\begin{array}{l}\text { Near/at a researcher's lab; neutral location; online or remote; unclear } \\
\text { location; participants' residence, school, work, or similar location; or no } \\
\text { user study; other }\end{array}$ & $\begin{array}{c}0.71 \\
(S D=0.20)\end{array}$ & Yes \\
\hline Participant groups & $\begin{array}{l}\text { People with disabilities; older adults; caregivers; specialists (e.g., } \\
\text { therapists or teachers); people without disabilities; no user study; other }\end{array}$ & $\begin{array}{c}0.88 \\
(S D=0.20)\end{array}$ & Yes \\
\hline Use of proxies & Yes; no & $\begin{array}{c}0.68 \\
(S D=0.00)\end{array}$ & No \\
\hline
\end{tabular}




\begin{tabular}{|c|c|c|c|}
\hline $\begin{array}{l}\text { Ability-based } \\
\text { comparisons }\end{array}$ & Yes; no & $\begin{array}{c}0.80 \\
(S D=0.00)\end{array}$ & No \\
\hline Issue addressed & $\begin{array}{l}\text { Increasing independence; increasing digital access; increasing physical } \\
\text { access; increasing understanding of users; supporting communication; or } \\
\text { personal informatics and changing behavior; other }\end{array}$ & $\begin{array}{c}0.63 \\
(S D=0.34)\end{array}$ & Yes \\
\hline Contribution type & Empirical; artifact; methodological; theoretical; dataset; survey & $\begin{array}{c}0.76 \\
(S D=0.39)\end{array}$ & Yes \\
\hline Participant count & $\begin{array}{l}\text { Blind or low-vision; deaf or hard of hearing; autism; intellectual or } \\
\text { developmental disability; motor or physical impairment; cognitive } \\
\text { impairment; older adult; general disability or accessibility; caregivers; } \\
\text { specialists (e.g., therapists or teachers); people without disabilities; other- } \\
\text { crowdworkers; other }\end{array}$ & $\mathrm{N} / \mathrm{A}$ & Yes \\
\hline
\end{tabular}

\section{RESULTS}

We first characterize the current state of accessibility research (2010-2019) in terms of focus areas, study methods, and inclusion of disabled and nondisabled participants before complementing these findings with a programmatic analysis of temporal trends from the full 26-year period (1994-2019).

\subsection{Communities of Focus, Research Problems and Contributions}

To understand where the accessibility research field invests its effort and what gaps might exist, we summarize what communities and research problems receive attention, and the types of research contributions made.

\subsubsection{Communities of Focus}

As shown in Table 2, accessibility research focuses disproportionately on visual accessibility: almost half of the papers (43.5\%, $N=220 / 506)$ were aimed at addressing the needs of BLV people followed by a precipitous drop to people with motor or physical disabilities $(14.2 \%, N=72)$ and people who are deaf or hard of hearing $(11.3 \%, N=57)$. The remaining communities of focus each accounted for under $10 \%$ of papers, including people with cognitive impairments $(9.1 \%, N=46)$, older adults $(8.9 \%, N=45)$, autism $(6.1 \%, N=31)$, and IDD $(2.8 \%, N=14)$. Additionally, $9.1 \%(N=46)$ of papers aimed to address the disability community in general, including investigations of assistive technology [135], interviews with disability activists [91], and accessibility adherence/knowledge across professions [106,123]. The code "other" was also applied to $9.1 \%(N=46)$ of papers, of which 20 had no additional code; further analysis revealed that these 20 focused primarily on color vision accessibility $(N=7)$, such as work by Flatla et al. [41,96], in addition to mental health [127,163], special education [89], and learning disability topics more generally $[25,126]$.

Table 2: The frequency of applied codes for community of focus, issues addressed, and contribution type.

\begin{tabular}{|c|c|c|c|c|c|c|c|c|}
\hline $\begin{array}{l}\text { Community of } \\
\text { Focus }\end{array}$ & $\begin{array}{l}\text { Papers } \\
\text { w/ Code }\end{array}$ & $\begin{array}{l}\text { This Code } \\
\text { Only }\end{array}$ & Issue Addressed & $\begin{array}{l}\text { Papers } \\
\text { w/ Code }\end{array}$ & $\begin{array}{l}\text { This Code } \\
\text { Only }\end{array}$ & $\begin{array}{l}\text { Contribution } \\
\text { Type }\end{array}$ & $\begin{array}{l}\text { Papers } \\
\text { w/ Code }\end{array}$ & $\begin{array}{l}\text { This Code } \\
\text { Only }\end{array}$ \\
\hline$\overline{B L V}$ & $\begin{array}{l}220 \\
(43.5 \%)\end{array}$ & $\begin{array}{l}208 \\
(41.1 \%)\end{array}$ & Digital Access & $\begin{array}{l}186 \\
(36.8 \%)\end{array}$ & $\begin{array}{l}122 \\
(24.1 \%)\end{array}$ & Empirical & $\begin{array}{l}305 \\
(60.3 \%)\end{array}$ & $\begin{array}{l}171 \\
(33.8 \%)\end{array}$ \\
\hline Motor/Physical & $\begin{array}{l}72 \\
(14.2 \%)\end{array}$ & $\begin{array}{l}59 \\
(11.7 \%)\end{array}$ & $\begin{array}{l}\text { Understanding } \\
\text { Users }\end{array}$ & $\begin{array}{l}139 \\
(27.5 \%)\end{array}$ & $\begin{array}{l}89 \\
(17.6 \%)\end{array}$ & Artifact & $\begin{array}{l}281 \\
(55.5 \%)\end{array}$ & $\begin{array}{l}182 \\
(36.0 \%)\end{array}$ \\
\hline DHH & $\begin{array}{l}57 \\
(11.3 \%)\end{array}$ & $43(8.5 \%)$ & Physical Access & $\begin{array}{l}105 \\
(20.8 \%)\end{array}$ & $26(5.1 \%)$ & Theoretical & $44(8.7 \%)$ & $6(1.2 \%)$ \\
\hline
\end{tabular}




\begin{tabular}{|c|c|c|c|c|c|c|c|c|}
\hline Cognitive & $46(9.1 \%)$ & $29(5.7 \%)$ & Independence & $\begin{array}{l}93 \\
(18.4 \%)\end{array}$ & $14(2.8 \%)$ & Methodological & $16(3.2 \%)$ & $2(0.4 \%)$ \\
\hline General Disability & $46(9.1 \%)$ & $31(6.1 \%)$ & Communication & $\begin{array}{l}81 \\
(16.0 \%)\end{array}$ & 45 (8.9\%) & Dataset & $7(1.4 \%)$ & $2(0.4 \%)$ \\
\hline Older Adult & 45 (8.9\%) & $29(5.7 \%)$ & Behavior Change & $39(7.7 \%)$ & 19 (3.8\%) & Survey & $3(0.6 \%)$ & $0(0.0 \%)$ \\
\hline Autism & $31(6.1 \%)$ & $21(4.2 \%)$ & Other & $\begin{array}{l}59 \\
(11.7 \%)\end{array}$ & $25(4.9 \%)$ & & & \\
\hline $\begin{array}{l}\text { IDD } \\
\text { Other }\end{array}$ & $\begin{array}{l}14(2.8 \%) \\
46(9.1 \%)\end{array}$ & $\begin{array}{l}8(1.6 \%) \\
20(4.0 \%)\end{array}$ & & & & & & \\
\hline
\end{tabular}

Because papers could be coded with more than one community of focus, $7.1 \%(N=36)$ received multiple codes (not considering the code "other"). We analyzed co-occurrence patterns and found that some communities were much more likely to appear on their own than with others. Most notably, a vast majority of BLV papers ( $94.5 \%$ of 220 papers) had a singular focus. Of the twelve exceptions, eight were marked with general disability, two with older adult, two with motor/physical, and one with cognitive impairment. In contrast, the IDD code was the most likely to co-occur with another code $(N=6,42.9 \%$ of 14 papers), which is often due to its appearance with people with autism $(N=5,35.7 \%)$ and people with cognitive impairments $(N=1,7.1 \%)$. The older adults code also commonly co-occurred ( $N=16,35.6 \%$ of 45 papers) which emphasizes the common disability-related focus of research with older adults in the accessibility community, such as designing for older adults with tremor [113,153] or mild cognitive impairment $[97,103]$.

\subsubsection{Issues Addressed}

When examining the research aims of papers in our dataset, the three most common objectives were to increase digital access through a technology innovation $(36.8 \%, N=186 / 506)$, understand user needs, preferences and abilities (27.5\%, $N=139)$, and increase physical world access (20.8\%, $N=105)$-see Table 2 . We also identified and coded for three more specific and less frequent areas of investigation: increasing independence $(18.4 \%, N=93)$, supporting communication $(16.0 \%, N=81)$, and personal informatics and/or behavior change $(7.7 \%, N=39)$; an additional $4.9 \%$ of papers $(N=25)$ received the sole code of "other". Again, multiple codes could apply, such as if a paper aimed to increase physical world access but also framed that innovation as increasing independence (e.g., $[18,61])$.

Perhaps more interestingly, research papers addressed different issues depending on the community of focus. The DHH community papers contrasted most strongly with overall trends: almost two thirds of DHH papers $(64.9 \%$ of 57 total) addressed communication, such as real-time captioning $[83,119]$ or signing avatar technology $[65,78]$. Similarly, papers focusing on the autism community most commonly addressed behavior change and increasing understanding of users-each of which appeared in $32.3 \%$ of the 31 autism papers-while increasing independence (42.9\%) and behavior change (35.7\%) were the top two issues for the 14 IDD papers. For example, a smartwatch application for people with IDDs aimed to change behavior by "notifying the student to keep [himself]/herselffocused, to ask or answer questions, to participate in group discussions and to moderate his/her voice (speaking more or less loudly)" [166], while for autistic students: "MOSOCO suggests skill appropriate do's (e.g., "smile if somebody looks at you") and don'ts (e.g., "don't stare")" [39]. In contrast, the remaining communities of focus more closely mirrored overall trends. For BLV and motor/physical papers, increasing digital access was the most common issue addressed (48.2\% of $220 \mathrm{BLV}$ papers and $40.3 \%$ of 72 motor/physical papers), while for the older adult, cognitive impairment, and general disability communities, the most common issue addressed was to understand users $(46.7 \%$ of $45,37.0 \%$ of 46 , and $47.8 \%$ of 46 papers, respectively). 


\subsubsection{Contribution Type}

The above issues were addressed primarily through empirical contributions $(60.3 \%, N=305 / 506)$ - often to understand a populations' view toward or use of a technology (e.g., $[27,75,78])$ —or artifact contributions $(55.5 \%$, $N=281$ ), building a tool and evaluating it with users (e.g. $[69,101,131])$. These two contribution types frequently occurred in combination $(18.4 \%, N=93)$. The remaining five contribution types occurred considerably less frequently, with theoretical being the next most popular $(8.7 \%, N=44)$, including Mankoff et al.'s disability studies as a source of critical inquiry paper [100] and Bennett et al.'s work on interdependence as a frame for assistive technology [16]. Only 16 papers (3.2\%) made methodological contributions, such as Trewin et al.'s [147] Usage of Subjective Scales in Accessibility Research and Holone and Herstad's [62] Three Tensions in Participatory Design for Inclusion. Dataset contributions were even rarer, at 1.4\% ( $N=7)$ of papers $[12,42,66,90,150,160,162]$-two of which received no other contribution type code: Flores and Manduchi's WeAllWalk dataset [42] and Wolter et al.'s CADENCE corpus for inclusive voice interface design [160]. Finally, literature survey was the least common contribution type, occurring in only three papers (0.6\%), including Carter et al.'s survey of autism research [33], Abbott et al.'s work on anonymization practices in aging and accessibility research [1], and the aforementioned Trewin et al.'s [147] work on subjective scales.

\subsection{Prevailing Research Methods}

While the above section analyzed where the accessibility community invests attention, here we explore how this research was conducted, who is included in research studies, and other decisions related to study design.

\subsubsection{What overall research methods are most popular?}

Reflecting the human-centered design orientations of the ASSETS and CHI communities, accessibility papers overwhelmingly include user studies: $94.3 \%(N=477)$ of 506 papers. For the 29 papers that did not include user studies, research methods included analyses of existing content (e.g., forum posts [30,72]), algorithmic/system analyses (e.g., [35,96]), literature reviews (e.g., [1,147]), and theoretical contributions (e.g., [51,124]).

Focusing on only the 477 user-study papers, the three most common methods-accounting for $84.1 \%$ of papers $(N=401 / 477)$ - were interviews $(42.1 \%, N=201)$, usability testing $(41.7 \%, N=199)$, and controlled experiments $(34.6 \%, N=165)$. Interestingly, a majority of papers $(56.4 \%, N=269)$ were coded with multiple user study methods, with surveys, interviews, and focus groups most commonly co-occurring with others. For the papers that included only a single method $(35.6 \%, N=180 / 506)$, the most common methods were controlled experiment $(30.6 \%$, $N=55 / 180)$ and usability testing $(25.6 \%, N=46 / 180)$. Additionally, $16.1 \%$ of user study papers $(N=77 / 477)$ were coded as other. For these, besides four papers $[42,43,77,146]$ that evaluated algorithm/model performance, all remaining other codes added nuance to a non-other code (e.g., specifying that usability testing was performed via contextual inquiry [6,23]).

Table 3: The frequency of applied codes for study method, study location, and participant group for the 477 user-study papers.

\begin{tabular}{|c|c|c|c|c|c|c|c|c|}
\hline \multirow[b]{2}{*}{ Study Method } & \multicolumn{2}{|c|}{ Papers w/ This Code } & \multirow[b]{2}{*}{ Study Location } & \multicolumn{2}{|c|}{ Papers w/ This Code } & \multirow{2}{*}{$\begin{array}{l}\text { Participant } \\
\text { Group }\end{array}$} & \multicolumn{2}{|c|}{ Papers w/ This Code } \\
\hline & Code & Only & & Code & Only & & Code & Only \\
\hline Interviews & $\begin{array}{l}201 \\
(42.1 \%)\end{array}$ & $27(5.7 \%)$ & Unclear & $\begin{array}{l}189 \\
(39.6 \%)\end{array}$ & $\begin{array}{l}133 \\
(27.9 \%)\end{array}$ & $\begin{array}{l}\text { People } \\
\text { w/Disability }\end{array}$ & $\begin{array}{l}404 \\
(84.7 \%)\end{array}$ & $\begin{array}{l}214 \\
(44.9 \%)\end{array}$ \\
\hline Usability Testing & $\begin{array}{l}199 \\
(41.7 \%)\end{array}$ & $46(9.6 \%)$ & $\begin{array}{l}\text { Home/Freq. } \\
\text { Loc. }\end{array}$ & $\begin{array}{l}138 \\
(28.9 \%)\end{array}$ & $\begin{array}{l}85 \\
(17.8 \%)\end{array}$ & $\begin{array}{l}\text { People w/out } \\
\text { Disab. }\end{array}$ & $\begin{array}{l}110 \\
(23.1 \%)\end{array}$ & $5(1.0 \%)$ \\
\hline Controlled Exp. & $\begin{array}{l}165 \\
(34.6 \%)\end{array}$ & $\begin{array}{l}55 \\
(11.5 \%)\end{array}$ & Lab & $\begin{array}{l}130 \\
(27.3 \%)\end{array}$ & $\begin{array}{l}93 \\
(19.5 \%)\end{array}$ & Specialist & $\begin{array}{l}81 \\
(17.0 \%)\end{array}$ & $9(1.9 \%)$ \\
\hline
\end{tabular}




\begin{tabular}{|c|c|c|c|c|c|c|c|c|}
\hline Survey & $\begin{array}{l}122 \\
(25.6 \%)\end{array}$ & $6(1.3 \%)$ & Online/Remote & $\begin{array}{l}98 \\
(20.5 \%)\end{array}$ & $\begin{array}{l}48 \\
(10.1 \%)\end{array}$ & Caregivers & 45 (9.4\%) & $4(0.8 \%)$ \\
\hline Workshop/Design & 88 & $15(3.1 \%)$ & Neutral Loc. & $32(6.7 \%)$ & $15(3.1 \%)$ & Older Adult & $40(8.4 \%)$ & $15(3.1 \%)$ \\
\hline Field Study & $\begin{array}{l}85 \\
(17.8 \%)\end{array}$ & $22(4.6 \%)$ & Other & 7 (1.5\%) & $1(0.2 \%)$ & Other & $\begin{array}{l}53 \\
(11.1 \%)\end{array}$ & $23(4.8 \%)$ \\
\hline Focus Groups & $28(5.9 \%)$ & $4(0.8 \%)$ & & & & & & \\
\hline Case Study & $19(4.0 \%)$ & $1(0.2 \%)$ & & & & & & \\
\hline Other & $\begin{array}{l}77 \\
(16.1 \%)\end{array}$ & $4(0.8 \%)$ & & & & & & \\
\hline
\end{tabular}

\subsubsection{Where are studies conducted?}

HCI user studies are typically conducted in research labs, but allowing for other locations-such as from home or in community centers-may broaden who is able to participate. Of the 477 papers with user studies, 405 (84.9\%) specifically mentioned a location for at least one study, though nearly $40 \%$ still had at least one study location that was unclear (39.6\%, $N=189 / 477)$. While a substantial portion were laboratory/on-campus sites (32.1\%, $N=130 / 405)$, slightly more were at participants' home, work, or a place they visit frequently $(34.1 \%, N=138)$. Remote participation $(24.2 \%, N=98)$ and neutral locations like a community library $(7.9 \%, N=32)$ were also common. Non-campus locations were often selected to improve aspects of the research, like increasing ecological validity by studying a behavior or social interaction in context (e.g., $[55,114,157])$ or allowing for easier recruitment of communities (e.g., summer camp [2], care facility [152], or school [47]). Other times, locations were chosen to reduce travel burden or increase accessibility (e.g., [26,110,143,168]); for example, Zou et al. explained, "Participants were encouraged to choose a location of their preference. Fifteen chose their home, one chose a public library, one chose his office, and one chose the researcher's home" [168].

\subsubsection{Who is included in accessibility studies and what are the sample sizes?}

We examined who and how many participants are included in accessibility studies. For the 477 user-study papers, we found that most (90.1\%; $N=430 / 477$ ) included participants with disabilities and/or older adults (Table 3). For the 47 papers $(9.9 \%)$ that did not, almost half included specialists and/or caregivers $(38.3 \%, N=18 / 47)$ in proxy roles, which we describe further in Section 4.3. The remaining 29 papers either had nondisabled participants $(N=6)$ and/or had been marked as "other" $(N=24)$. For the former, papers focused on educating nondisabled people on accessibility issues [21,81], running disability simulations [48], and having nondisabled people test technologies that were designed to help people with disabilities [34]. For the 18 papers coded only as "other", 10 focused on ASL signers in general, without requiring that they be d/Deaf or hearing, such as papers evaluating sign language video quality [145].

Recruiting users in accessibility research can be challenging, especially when working with highly specific populations [132]. To assess sample size practices across these participant groups, we analyzed participant numbers in the 477 user-study papers. Twenty-six papers did not clearly report on participant numbers (e.g., [128]), leaving 451 papers for analysis. For this analysis, we further split out crowdsourced participants from the more general "other" code.

Overall, the median number of participants per paper was $18(I Q R=29.0, M=830.1, S D=16,140.3)$. However, breaking down these numbers into multiple participant groups per paper shows that samples specifically of participants with disabilities or older adults have a median of only $13(I Q R=13.0, M=62.0, S D=478.8)$. Table 4 shows this detail, with sample sizes ranging from a median of 9 (autism) to 28 (DHH), with many in the 9-16 range. 
Distributions were also highly skewed, with a few studies having 1,000+ participants (e.g., [92]) - particularly crowdsourced studies - and seven papers overall having only one or two participants. These smallest sample sizes came mostly from field studies $[5,22,68,90]$ such as Alankus et al.'s close work with one participant in studying stroke therapy [5]. Caregiver and specialist groups had relatively small sample size medians of 7.5 and 7.0, respectively, reflecting the advisory role these groups often play.

Table 4. Number of participants broken down by type of Participant Group and Community of Focus, the 451 of 477 papers with user studies and that clearly reported on sample size for at least one participant group.

\begin{tabular}{llllll}
\hline Group & Med & Mean & IQR & Range & Total Papers \\
\hline Other-Crowdworkers & 153 & $27,500.0$ & 755.0 & $15-351,960$ & 13 \\
DHH & 28 & 44.5 & 41.5 & $1-284$ & 35 \\
General DA & 19 & 24.0 & 14.5 & $3-55$ & 4 \\
Nondisabled & 16 & 97.8 & 26.0 & $2.0-3,323$ & 105 \\
Cognitive & 16 & 40.3 & 33.0 & $3-328$ & 29 \\
Older Adult & 15 & 32.8 & 18.3 & $2-519$ & 38 \\
BLV & 13 & 88.8 & 12.0 & $1-7,398$ & 208 \\
IDD & 11.5 & 16.4 & 10.3 & $2-48$ & 10 \\
Other/Unclear & 11 & 47.3 & 22.0 & $1-566$ & 61 \\
Motor/Physical & 10 & 15.3 & 11.0 & $1-102$ & 61 \\
Autism & 9 & 12.9 & 5.0 & $2-75$ & 23 \\
Caregivers & 7.5 & 11.0 & 8.8 & $1-43$ & 34 \\
Specialists & 7 & 14.2 & 11.0 & $1-80$ & 69 \\
\hline
\end{tabular}

\subsubsection{How widely are participatory methods used?}

Participatory design (PD) provides a method and vision for involving users of technology directly in its design [45]. Though PD has a long history within HCI [111], there are ongoing debates about what constitutes PD and the extent to which it "has become too diluted" [13], with papers using the term "participatory" for a wide variety of design activities and study lengths. For accessibility research, in particular, there are unique tensions, including the additional burden placed on PD participants for their "access labor" [17] and the inaccessibility of traditional participatory methods to certain communities, such as autistic people [46] or people with aphasia [73].

In our analysis, we found that $10.3 \%(N=49 / 477)$ of papers with a user study identified themselves as using PD or co-design. Some studies engaged participants in rich design processes such as crafting and bodystorming [104], play-acting [73], and ideating on prompts [64,67]. Others used participatory design to test an evolving research prototype, with the same or different users $[53,115,137]$. The number of sessions varied from single instances [64,115] to as many as 20 sessions [161]. Almost all participatory-design papers included disabled participants and/or older adults (95.9\%, $N=47 / 49)$, and a substantial portion also included other stakeholders, such as specialists, therapists, and teachers $(40.8 \%, N=20)$ and/or caregivers $(20.4 \%, N=10)$. Wu et al. [161], for example, included caregivers and specialists in the participatory design of a calendar app for memory loss, and Waddington et al. [154] involved both therapists and BLV people in designing an app for therapeutic exercises. Only two papers employing participatory design did not include disabled participants or older adults, both of which focused on enabling nondisabled stakeholders (teachers, occupational therapists) in 3D printing technologies for people with disabilities [31,59]. Finally, while PD was used across all communities of focus, it was most prevalent in papers on cognitive impairment $(21.7 \%, \mathrm{~N}=10 / 46)$ or IDD $(21.4 \%, N=3 / 14)$ compared with $6-17 \%$ for other communities of focus. 


\subsection{The Role of Nondisabled Participants, Caregivers and Specialists}

Accessibility work typically centers people with disabilities, yet caregivers, specialists, and nondisabled participants are also involved, often as stakeholders but also as proxies or comparison groups-two roles for which we explicitly coded.

\subsubsection{How and when are proxies used?}

Proxy use occurred in $8.0 \%$ of all user-study papers $(N=38 / 477)$, most often in conjunction with participants with disabilities ( $N=32$ of the 38 papers). Papers did not typically specify rationale for why proxies were used; however, for those that did, reasons ranged from lessening the burden on participants [57] to working around communication difficulties [109]. As an example of the latter, "Since some of our participants had verbal difficulties, we asked staff members to identify the preferred interests for each participant prior to the date of the study" [109].

Typically, proxies were specialists $(65.8 \%, N=25 / 38)$ and/or caregivers $(44.7 \%, N=17)$ and were asked to offer a disabled individual's perspective of a situation [24,85,138], behavior [8,165], and/or new technology [32,116]. For example, in a study from Boyd et al. [24], a parent discussed her autistic child's behavior: "I feel he doesn't know how close to get or how to close not to get [to other people]. It's like an abstract idea for him". Similarly, in a survey designed for people with motor impairments, Anthony et al. [8] reported that "in many cases, a third person completed the survey on the user's behalf, either because the primary user was a child or because it was difficult for the primary user to do". This input from proxies often complemented data from disabled participants, such as Carrington et al.'s [32] use of focus groups with doctors, therapists, and family members in addition to sessions with power wheelchair users.

When examining the use of proxies as a function of community of focus, we found that proxies were most common in studies focusing on autism $(22.6 \%, N=7 / 31)$, followed by cognitive impairment $(17.4 \%, N=8 / 46)$ and IDD $(21.4 \%, N=3 / 14)$. Common reasons included seeking the domain expertise of specialists or caregivers (e.g., IDD $[107,144]$, cognitive impairment [139]) and communication difficulties (e.g., autism [53,109], cognitive impairment [85]). At the other end of the spectrum, there were no instances of DHH-focused papers that included proxies.

\subsubsection{How and when are disabled and nondisabled participants compared?}

We identified 65 papers (13.6\%) that compared disabled and nondisabled participants (e.g., blind vs. sighted users or people with and without motor impairments), often to understand people's needs, experiences, or perceptions across varied abilities [11,82,108,126,149] but also to establish a comparative "baseline" or "control group" (e.g., $[60,92,102,167])$. As examples of the former, Kushalnagar et al. [82] studied how caption needs differ depending on hearing ability in a classroom deployment and Oh et al. examined differences in touchscreen use between BLV and sighted users as reported in an online survey [118]. These papers most commonly included controlled experiments $(N=41,63.1 \%)$, with nondisabled participants often acting as a control group. For example, Findlater et al. [40] investigated whether touch screen interaction "reduce[d] the performance gap between older and younger adults" compared to using a mouse.

Another use of ability-based comparisons was to understand differences between ability level to allow for collaboration between disabled and nondisabled individuals. Kacorri et al. [70], for example, compared images taken by blind and sighted users to "explore the benefits of having a sighted person training a blind user's personal object recognizer." Comparison can also be used to create or evaluate equitable experiences across ability levels, 
such as da Rocha Tomé Filho et al.'s [129] assessment of BLV and sighted participants' experiences in playing adapted board games.

\subsection{Historical Context: Programmatic Analysis of 26-year Temporal Trends}

While the qualitative coding analysis revealed current foci and methods employed in accessibility work, here we turn to longer-term temporal trends via a programmatic analysis of overall paper counts and keywords appearing in the author keywords, titles, and abstracts of papers from 1994-2019.

\subsubsection{The growth of accessibility research}

As shown in Figure 1, accessibility research has grown rapidly over the past 26 years: from 22 papers in 1994 ( 0 at CHI and 22 at ASSETS) to 95 in 2019 (55 at CHI and 40 at ASSETS). This growth is particularly pronounced within the last five years at $\mathrm{CHI}$, with the number of accessibility-related $\mathrm{CHI}$ papers overtaking the overall number of ASSETS papers in 2018, and the growth in accessibility papers outpacing the growth of CHI itself (Figure 1, right). In 2019, accessibility papers made up 7.8\% (55 of 702 papers) of all CHI papers-and the keyword "accessibility" was the second most common overall (behind "virtual reality") [170].

\subsubsection{Temporal trends in communities of focus, technologies, and methods}

As described in Section 3.2.2, to analyze more specific temporal trends over the 26 years, we categorized author keywords as relating to one of three themes (if applicable): communities of focus (i.e., users), technologies, and research methods. Within each theme, we combined similar keywords into higher-level keyword groups, such as grouping "low vision" and "blind" into "BLV"; see Supplementary Materials for the full list of groupings. We then counted the number of papers per year that used each of those keyword groups, normalizing the count if a given paper employed more than one keyword group within a theme. For example, if a paper had both BLV and older adult keywords, the count would be 0.5 toward BLV and 0.5 toward older adults. Table 5 shows the top 12 keyword groups for each of the three themes over the full 26 years, in addition to proportions of papers using those keywords over time (sparkline plots). To smooth the sparkline plots, we aggregated papers into five bins: 1994-1999, 20002004, 2005-2009, 2010-2014, and 2015-2019.
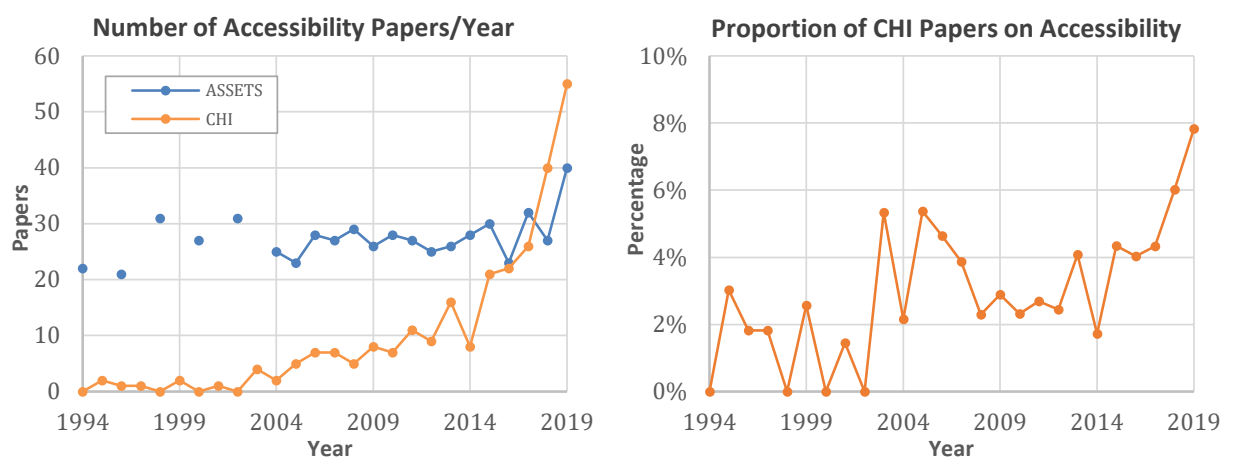
Figure 1: Accessibility paper counts at $\mathrm{CHI}$ and ASSETS over time (left) show that accessibility is growing as a field, especially the past five years. The percent of $\mathrm{CHI}$ papers on accessibility (right) shows that accessibility research has grown as a proportion of all $\mathrm{CHI}$ papers, reaching nearly $8 \%$ of $\mathrm{CHI}$ papers in 2019.

The main trends for community of focus are largely consistent with the earlier qualitative analysis, showing the high proportion of attention to the BLV community followed by motor/physical and DHH communities. Papers on older adults and people with cognitive impairments also appear consistently since the earliest years, with other communities of focus only appearing more recently, including autism and neurodiversity (2000-2004), color vision deficiency (2005-2009), and mental health (2010-2015). "Children" is a relatively common keyword for which we did not explicitly code, but that reflects that accessibility work often focuses on children's specific needs (e.g., $[47,53,55])$. Another new keyword here is "literacy", which can relate to areas ranging from tactile media consumption [142] to literacy issues related to understanding terms of service information [95].

For technology keywords, which we had not reported on in the qualitative analysis, temporal trends follow broader technology trends over time. "Web" is the all-time most popular technology keyword, but it dropped off in the past 10 years. "Mobile", in contrast, grew substantially before plateauing in the last five years. The general term "user interfaces" has also dropped since the early years, perhaps because it is redundant with HCI. To understand more recent changes in technology foci, we also identified which popular technology keyword groups have only appeared in the last 10 years. Examining the top 20 keyword groups from 2010-2019 reveals six that were not present in the top-20 list from 1994-2009: games, wearable computing, social computing, 3d printing and DIY, AR/MR/VR (augmented, mixed or virtual reality), and collaboration tools-all representing recent technology trends in accessibility and HCI more broadly.

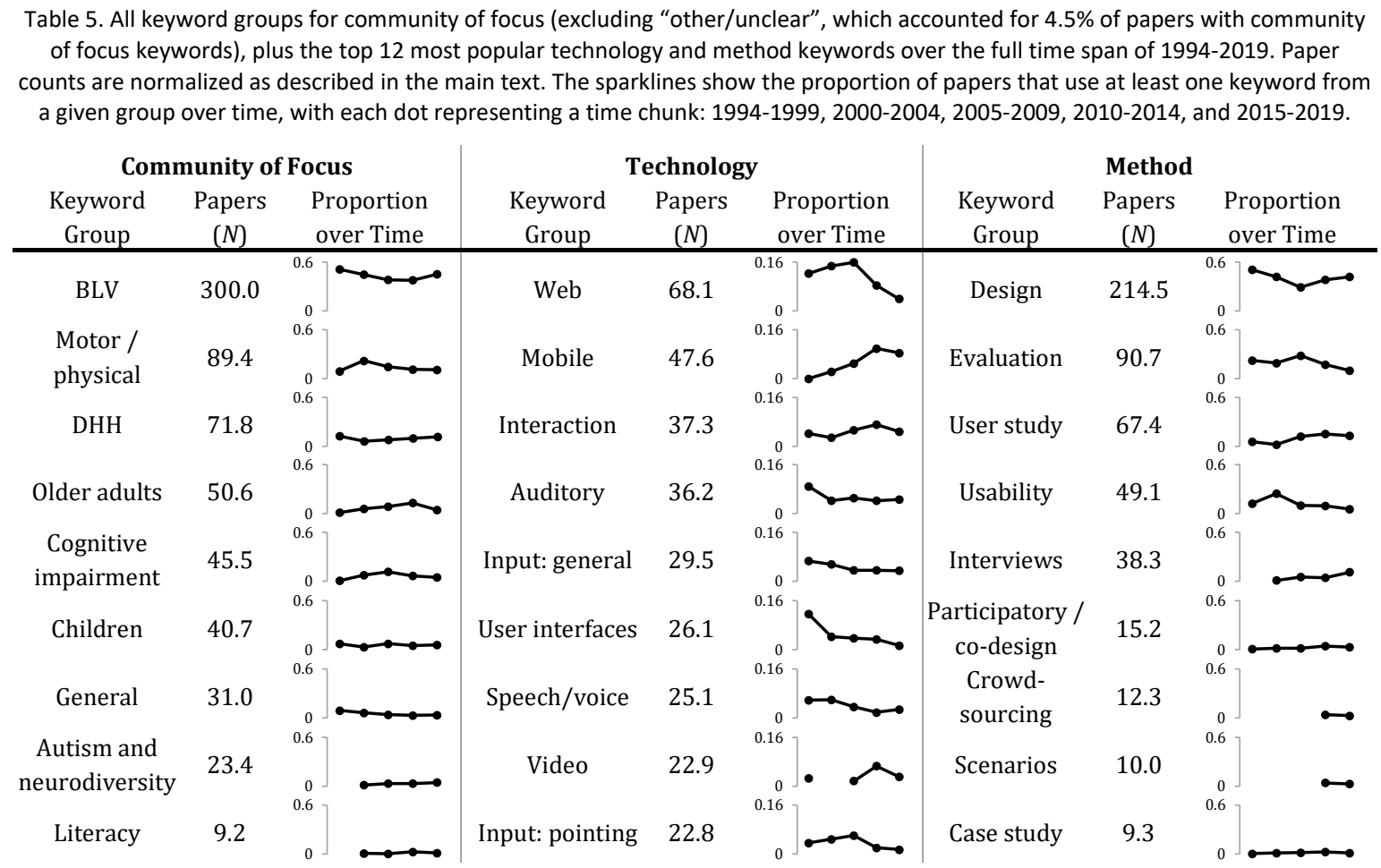




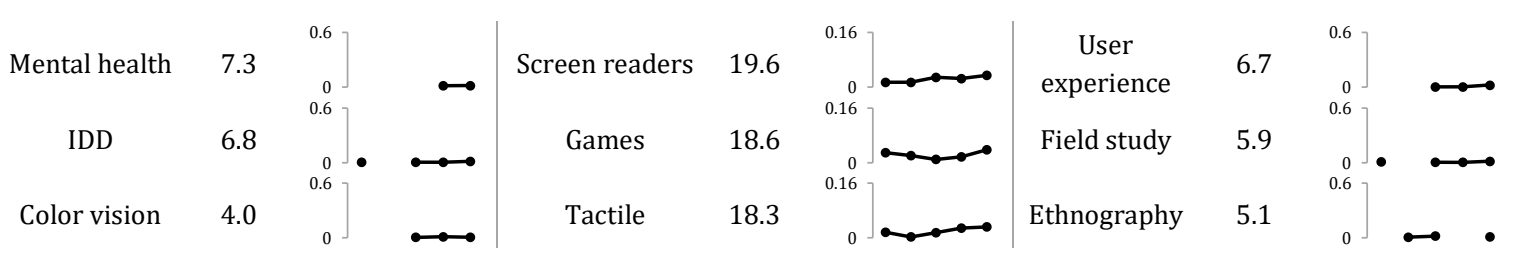

Finally, for methods, the generic terms "design", "evaluation", and "user study" are the most popular. Perhaps reflecting larger language and conceptual changes in HCI research and practice, "usability" drops over time while "user experience" only began to appear in 2005-2010. In terms of other specific user study methods, interviews appear to be increasing over time, only appearing for the first time in 2000-2004 and growing to $10.9 \%$ of method keywords in 2015-2019. However, we note that this number is considerably lower than the $42.1 \%$ of papers that we had coded as employing an interview method in Section 4.2.1, which may reflect the relative lack of method keywords compared to community of focus and technology keywords (34.1\% of papers had no method keywords). Other methods are infrequent but consistently present over the years, in line with our qualitative coding: participatory design, case studies, field studies, and the related method of ethnography. Finally, crowdsourcing unsurprisingly appears only within the last 10 years.

\section{DISCUSSION}

Accessibility research has grown substantially over the past few decades, proportionally outpacing the growth of $\mathrm{CHI}$ itself. This is a moment to celebrate and to reflect. In this first broad literature survey of accessibility work, we describe a sprawling research field that, while disproportionately focusing on blind and low vision users, encompasses many other communities and addresses a range of issues. We surface norms in accessibility research-norms that have been shaped by accessibility researchers, reviewers, and journal and conference leadership and that all members of our community should continually question and reassess. To help guide future accessibility research, we recap and discuss the more critical gaps and trends from our analysis, as well as implications for conducting similar literature surveys.

\subsection{Current Foci and Growth Opportunities in Accessibility Research}

Underpinning our work is the question of "what is accessibility research?". Accessibility has a home within HCI but touches on computer science, disability studies, gerontechnology, health, rehabilitation engineering, and other areas. In focusing on CHI and ASSETS, the two most popular conferences for HCI-focused accessibility work, we describe the core field but do not fully represent these peripheries nor do we fully capture contributions that might be more common in journals than in conferences (e.g., literature surveys or multi-study papers). Our decision to filter CHI papers to those that self-identified as accessibility focused [79] also further shaped our dataset and the conclusions we can draw, defining an expansive set of "accessibility" papers but also undoubtedly missing some that could arguably qualify.

Within that context, our analysis reveals who and what research problems are valued by the community. In terms of who, BLV people are by far the most common community of focus. We suspect that this skew is due to multiple interdependent factors including funding mechanisms, the popularity of BLV people in public disability discourse, and the apparent concreteness of visual accessibility problems to HCI researchers (e.g., how to make computer I/O accessible to a blind user). On the other hand, autism, IDD, cognitive impairment, and other areas are less common 
or have only appeared in the accessibility literature more recently. These lattermost areas and the equally important communities of focus that were coded as "other" point to opportunities for growth. Mental health issues and chronic illness, for example, are prominent in our society but not well-represented in the dataset, suggesting that HCI researchers could more actively pursue work in this space from a disability perspective. Adopting an accessibility or disability framing introduces questions around how technology and norms can adapt to be more inclusive of these individuals. Relatedly, we found that few papers included multiple communities of focus (7.1\%) or people with multiple disabilities $(<1.0 \%)^{9}$ : a critical omission that needs future work. Lastly, though not captured in our study, future work can follow Ogbonnaya-Ogburu et al. [117] to explicitly consider how participants' Deaf or disabled identities intersect with other aspects of their identity, such as race and gender, and the implications for design.

Accessibility research is also defined by what problems it tackles. Unsurprisingly, digital and physical accessibility problems, and attempts to understand related user needs are common. Perhaps more useful for shaping future work is to question why other research problems are popular only within some user communities. Focusing on communication for DHH users (64.9\% of DHH papers), for example, may well be appropriate for that community, who can experience communication as a disabling circumstance in a dominant hearing culture. In contrast, people with autism and IDD have repeatedly voiced that they do not want or need to change their behavior to make others more comfortable, but behavior change work is comparatively popular with the autistic and IDD communities (32.3\% and $35.7 \%$ of papers, respectively). We thus encourage accessibility researchers to reflect on what research problems they address, and whether those problems are indeed priorities for the communities they want to serve. Increasing representation of disabled researchers, as emphasized by Spiel et al. [141], can help further identify community needs and research foci, while reviewing literature in fields that elevate Deaf and disabled people's voices (e.g., Deaf studies and disability studies) is also critical.

Finally, a few other key areas of momentum are worth noting. As mentioned in Section 2 and related to the previous point, accessibility researchers are increasingly drawing on disability studies to inform their work (e.g., $[16,100,141])$. Additionally, with the increase of data-driven AI systems and accompanying ethical issues, as emphasized by a recent ASSETS workshop [148], we call for more "dataset" contributions that are rooted in accessibility knowledge-a relatively sparse contribution type in our survey. Finally, contributions on best practices for teaching accessibility, as explicitly introduced for the ASSETS conference in 2019, are needed to help grow capacity and expertise within industry.

\subsection{Engaging with Users in Accessibility Work}

Compared to HCI as a whole, accessibility research introduces unique questions about how to engage with disabled participants and what role nondisabled participants, including specialists and caregivers, should have.

Accessibility research frequently includes disabled participants or older adults, but concerns can arise in the extent to which study procedures are accessible to these participants and the depth of their engagement. Regarding accessible procedures, the use of study locations that are accessible and/or convenient to participants, such as homes or community centers, is a positive research community norm. For depth of engagement, a relatively small number of papers employed participatory design (10\% of user-study papers), a potentially powerful method to

9 We recorded people with multiple disabilities as "other" in our dataset rather than selecting two communities of focus categories since 1) they occurred very infrequently, and 2) the experience of a deaf-blind individual is not the sum of the experiences of a deaf individual and a blind individual. 
empower end users in design. However, some papers that used participatory design terminology included only single sessions with participants, reflecting recent critiques on what constitutes participatory design [13]. Moreover, there are unique challenges in an accessibility context, such as the potential overreliance and underacknowledged use of people with disabilities for their "access labor" in PD [17] and the inaccessibility of some PD methods to certain communities, such as people with aphasia [73]. We suggest that authors think carefully about these tradeoffs and that they discuss the tensions in their publications.

Another persistent challenge in accessibility work is how to recruit sufficiently large samples for user studies [132]. We found a median sample size of 13 (SD=478.8) for disabled and older adult participant groups, but some specific communities of focus had much smaller samples (e.g., samples of autistic people had a median of 9). The median of 13 is also lower than a recent analysis of CHI 2020 papers in general, which found lab, field, and interview studies had a median of 15-16 participants and remote studies had 182 [80]. We argue, however, that these small sample sizes are not necessarily a limitation, especially given the potential for accessibility researchers to burden participants by repeatedly sampling from small populations and the difficulty of participation for some people (e.g., those with ALS) [17]. Methods that support smaller sample sizes (e.g., case studies, single-subject experiments) or less interaction with participants can address these problems [132], though these methods were rare in our dataset: only $4 \%$ of papers included case studies with participants and 6\% employed methods that did not require user studies. Content analyses and online ethnographies of user-generated information such as social media posts, videos, or other online content (e.g., [56,72,122]) are particularly promising for supporting insight while requiring less direct participant engagement. We encourage the community to carefully consider broader HCI and methodological norms and how they apply to accessibility research, where it is difficult to recruit large numbers of participants. Moreover, we encourage reviewers to engage in discussions with the authors and program committee before dismissing an accessibility paper based on a small sample size.

Finally, our analysis reveals the roles of nondisabled participants in accessibility work. Two of these rolesability-based comparisons and proxy participation-can sometimes be useful but must be approached with caution due to the risk of reinforcing normative, ableist beliefs. Comparisons can highlight divergent experiences as evidence in calling for a more just, accessible world, but when nondisabled people are conceptualized as the baseline "normal" there is also the danger of perpetuating rather than dismantling ableism. Disability studies has long challenged frameworks that place "normal" as the goal for which disabled people should strive [37]. The use of proxy participants raises similar ethical dilemmas. For both ability-based comparisons and proxies, we recommend that researchers first question their own motivation: is the proxy usage justified or is it simply easier than alternatives, such as learning how to alter their communication style to better match the participant's style (as demonstrated by Spiel et al. [191])? For proxies, another strategy is to engage with both disabled participants and proxies to triangulate the data collected from both (e.g., [138]) and/or to allow the disabled participants to confirm or correct information from the proxies (e.g., [74]). Regardless, for both comparisons and proxy use, we call on researchers to justify their decisions about these issues, which are often complex and nuanced, so that reviewers and other readers can effectively assess and critique the work.

\subsection{Reflections on Our Research Process and Limitations}

Rigorously curating a literature survey dataset and applying codes was challenging and effortful, and we would be skeptical of literature survey papers that do not discuss these details. The ACM provided us with a metadata dump of the $\mathrm{CHI}$ and ASSETS proceedings within our target time period, but cleaning that data took substantial manual 
effort to ensure the number of papers closely matched expected counts. Further, following our codebook development process that included IRR, we manually and programmatically looked for inconsistencies in the coded data and spent hours discussing difficult papers. In sum, these challenges have implications for how to assess future literature reviews and the importance for researchers to provide sufficient methodological detail. The data cleaning challenges are likely to be magnified when including publications from multiple sources (e.g., ACM, IEEE, Elsevier, Thomson Reuters as in [19]) and relying on purely automated analyses (e.g., [14,63,93]). And, while IRR may not be appropriate for reviews using a critical discourse analysis or other thematic approach (e.g., [140]), it is key for more quantitative reviews.

In conducting this work, we also encountered highly varied language use across papers, which impacted our codebook and the conclusions we can draw from the work. Expanding on a similar conclusion by Brulé et al.'s [29] research with BLV users, blind or low vision people were referred to as "blind", "visually impaired", "low vision", "differently sighted", or having "vision loss". More difficult for our coding was the inconsistency in how papers described neurodiversity, and cognitive and/or learning disabilities. People with autism, IDD, or cognitive impairments were often grouped together in participant descriptions, for example, saying "special education students" or "psychosocial disabilities" (e.g., $[89,127])$. In assigning these codes, we yielded to authors' descriptions of the work (e.g., using the term "cognitive impairment" or "developmental disability"), and coded more general or unclear descriptions as "other". We acknowledge that other researchers may have derived different code categories, perhaps more coarse- or fine-grained ones, to describe neurodiversity and cognition-related disabilities.

Finally, beyond these challenges, our work has other limitations. First, our approach to filtering CHI papers and the codebook we derived are shaped by our positionality, and other researchers may have defined these steps differently. Second, though necessary for our quantitative study method, concretizing boundaries of what qualifies as a certain disability and what does not is itself somewhat problematic. The lines between communities are often overlapping or ill-defined; for example, someone who has an IDD or is a stroke survivor may encounter cognitive accessibility issues, physical accessibility issues, or both, and these distinctions are not always clear nor relevant in work focusing on functional differences rather than identity. Third, we scoped to only two popular conferences for accessibility work (CHI and ASSETS) so that we could conduct in-depth analyses. The norms and contributions (e.g., populations studied, sample sizes) identified in our study do not necessarily generalize to research published at other venues, including other HCI conferences and journals such as TOCHI and TACCESS.

\section{CONCLUSION}

In conclusion, our paper reflects on the field of accessibility's growth and history for the past 26 years, its implications for the field's current work, and where the community should go from here. Through a combination of qualitative and quantitative analysis strategies, we contribute both a deep understanding of work in the past decade and a broader overview of changes in the community for the past 26 years. While our results and discussion highlight a variety of beneficial practices already adopted in the community, we also suggest areas for improvement. For example, we encourage better representation in the community and promote the need to be cognizant of how ableism can surreptitiously be incorporated into research norms. We hope that researchers utilize our data and ideas to reflect and discuss with others the future of accessibility research. 


\section{ACKNOWLEDGMENTS}

We thank Rose Guttman and Emily Rosenfield for their early help in data analysis and thank the ACM for supplying the data for our study. This work was funded in part by the National Science Foundation under grants IIS-1818594 and IIS-1652339 as well as the UW Center for Research and Education on Accessible Technology and Experiences (CREATE).

\section{REFERENCES}

1. Jacob Abbott, Haley MacLeod, Novia Nurain, Gustave Ekobe, and Sameer Patil. 2019. Local Standards for Anonymization Practices in Health, Wellness, Accessibility, and Aging Research at CHI. In Proceedings of the 2019 CHI Conference on Human Factors in Computing Systems (CHI '19), 1-14. https://doi.org/10.1145/3290605.3300692

2. Ali Abdolrahmani, William Easley, Michele Williams, Stacy Branham, and Amy Hurst. 2017. Embracing Errors: Examining How Context of Use Impacts Blind Individuals' Acceptance of Navigation Aid Errors. In Proceedings of the 2017 CHI Conference on Human Factors in Computing Systems (CHI '17), 4158-4169. https://doi.org/10.1145/3025453.3025528

3. ACM ASSETS. 2020. ASSETS 2020 Call for Papers (CFP). Retrieved August 8, 2020 from https://assets20.sigaccess.org/call_for_papers.html

4. ACM CHI2021. CHI2021: Selecting A Subcommitee: Accessibility and Aging. Retrieved August 10, 2020 from https://chi2021.acm.org/for-authors/presenting/papers/selecting-a-subcommittee\#Accessibility-andAging

5. Gazihan Alankus, Rachel Proffitt, Caitlin Kelleher, and Jack Engsberg. 2010. Stroke therapy through motionbased games: a case study. In Proceedings of the 12th international ACM SIGACCESS conference on Computers and accessibility (ASSETS '10), 219-226. https://doi.org/10.1145/1878803.1878842

6. Khaled Albusays, Stephanie Ludi, and Matt Huenerfauth. 2017. Interviews and Observation of Blind Software Developers at Work to Understand Code Navigation Challenges. In Proceedings of the 19th International ACM SIGACCESS Conference on Computers and Accessibility (ASSETS '17), 91-100. https://doi.org/10.1145/3132525.3132550

7. Elena M. Andresen, Victoria J. Vahle, and Donald Lollar. 2001. Proxy reliability: Health-related quality of life (HRQoL) measures for people with disability. Quality of Life Research 10, 7: 609-619. https://doi.org/10.1023/A:1013187903591

8. Lisa Anthony, YooJin Kim, and Leah Findlater. 2013. Analyzing user-generated youtube videos to understand touchscreen use by people with motor impairments. In Proceedings of the SIGCHI Conference on Human Factors in Computing Systems (CHI '13), 1223-1232. https://doi.org/10.1145/2470654.2466158

9. Trent Apted, Judy Kay, and Aaron Quigley. 2006. Tabletop sharing of digital photographs for the elderly. In Proceedings of the SIGCHI Conference on Human Factors in Computing Systems (CHI '06), 781-790. https://doi.org/10.1145/1124772.1124887

10. Association for Computing Machinery (ACM). 1992. Communications of the ACM. Communications of the ACM 35,5 .

11. Shiri Azenkot and Nicole B. Lee. 2013. Exploring the use of speech input by blind people on mobile devices. In Proceedings of the 15th International ACM SIGACCESS Conference on Computers and Accessibility (ASSETS '13), 1-8. https://doi.org/10.1145/2513383.2513440

12. Fabio Ballati, Fulvio Corno, and Luigi De Russis. 2018. Assessing Virtual Assistant Capabilities with Italian Dysarthric Speech. In Proceedings of the 20th International ACM SIGACCESS Conference on Computers and Accessibility (ASSETS '18), 93-101. https://doi.org/10.1145/3234695.3236354

13. Liam Bannon, Jeffrey Bardzell, and Susanne Bødker. 2018. Introduction: Reimagining Participatory DesignEmerging Voices. ACM Transactions on Computer-Human Interaction 25, 1: 1:1-1:8. https://doi.org/10.1145/3177794

14. Christoph Bartneck and Jun Hu. 2009. Scientometric analysis of the CHI proceedings. In Proceedings of the SIGCHI Conference on Human Factors in Computing Systems (CHI '09), 699-708. https://doi.org/10.1145/1518701.1518810 
15. Gökçe Elif Baykal, Maarten Van Mechelen, and Eva Eriksson. 2020. Collaborative Technologies for Children with Special Needs: A Systematic Literature Review. In Proceedings of the $2020 \mathrm{CHI}$ Conference on Human Factors in Computing Systems (CHI '20), 1-13. https://doi.org/10.1145/3313831.3376291

16. Cynthia L. Bennett, Erin Brady, and Stacy M. Branham. 2018. Interdependence as a Frame for Assistive Technology Research and Design. In Proceedings of the 20th International ACM SIGACCESS Conference on Computers and Accessibility (ASSETS '18), 161-173. https://doi.org/10.1145/3234695.3236348

17. Cynthia L. Bennett, Burren Peil, and Daniela K. Rosner. 2019. Biographical Prototypes: Reimagining Recognition and Disability in Design. In Proceedings of the 2019 on Designing Interactive Systems Conference (DIS '19), 35-47. https://doi.org/10.1145/3322276.3322376

18. Tapomayukh Bhattacharjee, Maria E. Cabrera, Anat Caspi, Maya Cakmak, and Siddhartha S. Srinivasa. 2019. A Community-Centered Design Framework for Robot-Assisted Feeding Systems. In The 21st International ACM SIGACCESS Conference on Computers and Accessibility (ASSETS '19), 482-494. https://doi.org/10.1145/3308561.3353803

19. Alexy Bhowmick and Shyamanta M. Hazarika. 2017. An insight into assistive technology for the visually impaired and blind people: state-of-the-art and future trends. Journal on Multimodal User Interfaces 11, 2: 149-172. https://doi.org/10.1007/s12193-016-0235-6

20. Alexy Bhowmick and Shyamanta M. Hazarika. 2017. An insight into assistive technology for the visually impaired and blind people: state-of-the-art and future trends. Journal on Multimodal User Interfaces 11, 2: 149-172. https://doi.org/10.1007/s12193-016-0235-6

21. Jeffrey P. Bigham, Jeremy T. Brudvik, and Bernie Zhang. 2010. Accessibility by demonstration: enabling end users to guide developers to web accessibility solutions. In Proceedings of the 12th international ACM SIGACCESS conference on Computers and accessibility (ASSETS '10), 35-42. https://doi.org/10.1145/1878803.1878812

22. Rolf Black, Annalu Waller, Nava Tintarev, Ehud Reiter, and Joseph Reddington. 2011. A mobile phone based personal narrative system. In The proceedings of the 13th international ACM SIGACCESS conference on Computers and accessibility (ASSETS '11), 171-178. https://doi.org/10.1145/2049536.2049568

23. Fatima A. Boujarwah, Nazneen, Hwajung Hong, Gregory D. Abowd, and Rosa I. Arriaga. 2011. Towards a framework to situate assistive technology design in the context of culture. In The proceedings of the 13th international ACM SIGACCESS conference on Computers and accessibility (ASSETS '11), 19-26. https://doi.org/10.1145/2049536.2049542

24. LouAnne E. Boyd, Xinlong Jiang, and Gillian R. Hayes. 2017. ProCom: Designing and Evaluating a Mobile and Wearable System to Support Proximity Awareness for People with Autism. In Proceedings of the 2017 CHI Conference on Human Factors in Computing Systems (CHI '17), 2865-2877. https://doi.org/10.1145/3025453.3026014

25. LouAnne E. Boyd, Kathryn E. Ringland, Heather Faucett, Alexis Hiniker, Kimberley Klein, Kanika Patel, and Gillian R. Hayes. 2017. Evaluating an iPad Game to Address Overselectivity in Preliterate AAC Users with Minimal Verbal Behavior. In Proceedings of the 19th International ACM SIGACCESS Conference on Computers and Accessibility (ASSETS '17), 240-249. https://doi.org/10.1145/3132525.3132551

26. Robin Brewer, Meredith Ringel Morris, and Anne Marie Piper. 2016. "Why would anybody do this?": Understanding Older Adults' Motivations and Challenges in Crowd Work. In Proceedings of the 2016 CHI Conference on Human Factors in Computing Systems (CHI '16), 2246-2257. https://doi.org/10.1145/2858036.2858198

27. Robin N. Brewer and Vaishnav Kameswaran. 2019. Understanding Trust, Transportation, and Accessibility through Ridesharing. In Proceedings of the 2019 CHI Conference on Human Factors in Computing Systems (CHI '19), 1-11. https://doi.org/10.1145/3290605.3300425

28. Emeline Brulé, Brianna J Tomlinson, Oussama Metatla, Christophe Jouffrais, and Marcos Serrano. 2020. Review of Quantitative Empirical Evaluations of Technology for People with Visual Impairments. In Proceedings of the 2020 CHI Conference on Human Factors in Computing Systems (CHI '20), 1-14. https://doi.org/10.1145/3313831.3376749

29. Emeline Brulé, Brianna J. Tomlinson, Oussama Metatla, Christophe Jouffrais, and Marcos Serrano. 2020. Review of Quantitative Empirical Evaluations of Technology for People with Visual Impairments. In Proceedings of the 2020 CHI Conference on Human Factors in Computing Systems (CHI '20), 1-14. https://doi.org/10.1145/3313831.3376749 
30. Erin Buehler, Stacy Branham, Abdullah Ali, Jeremy J. Chang, Megan Kelly Hofmann, Amy Hurst, and Shaun K. Kane. 2015. Sharing is Caring: Assistive Technology Designs on Thingiverse. In Proceedings of the 33rd Annual ACM Conference on Human Factors in Computing Systems (CHI '15), 525-534. https://doi.org/10.1145/2702123.2702525

31. Erin Buehler, Shaun K. Kane, and Amy Hurst. 2014. ABC and 3D: opportunities and obstacles to 3D printing in special education environments. In Proceedings of the 16th international ACM SIGACCESS conference on Computers \& accessibility (ASSETS '14), 107-114. https://doi.org/10.1145/2661334.2661365

32. Patrick Carrington, Amy Hurst, and Shaun K. Kane. 2014. Wearables and chairables: inclusive design of mobile input and output techniques for power wheelchair users. In Proceedings of the SIGCHI Conference on Human Factors in Computing Systems (CHI '14), 3103-3112. https://doi.org/10.1145/2556288.2557237

33. Elizabeth J. Carter and Jennifer Hyde. 2015. Designing Autism Research for Maximum Impact. In Proceedings of the 33rd Annual ACM Conference on Human Factors in Computing Systems (CHI '15), 2801-2804. https://doi.org/10.1145/2702123.2702471

34. Brendan Cassidy, Janet C. Read, and I. Scott MacKenzie. 2019. An Evaluation of Radar Metaphors for Providing Directional Stimuli Using Non-Verbal Sound. In Proceedings of the 2019 CHI Conference on Human Factors in Computing Systems (CHI '19), 1-8. https://doi.org/10.1145/3290605.3300289

35. Gabriel J. Cler and Cara E. Stepp. 2017. Development and Theoretical Evaluation of Optimized Phonemic Interfaces. In Proceedings of the 19th International ACM SIGACCESS Conference on Computers and Accessibility (ASSETS '17), 230-239. https://doi.org/10.1145/3132525.3132537

36. Kate Cox. 2019. Accessibility, the future, and why Domino's matters. Ars Technica. Retrieved September 8, 2020 from https://arstechnica.com/tech-policy/2019/10/accessibility-the-future-and-why-dominosmatters/

37. Lennard J. Davis. 2013. The Disability Studies Reader. Routledge. https://doi.org/10.4324/9780203077887

38. Elizabeth Ellcessor. 2010. Bridging Disability Divides. Information, Communication \& Society 13, 3: $289-308$. https://doi.org/10.1080/13691180903456546

39. Lizbeth Escobedo, David H. Nguyen, LouAnne Boyd, Sen Hirano, Alejandro Rangel, Daniel Garcia-Rosas, Monica Tentori, and Gillian Hayes. 2012. MOSOCO: a mobile assistive tool to support children with autism practicing social skills in real-life situations. In Proceedings of the SIGCHI Conference on Human Factors in Computing Systems (CHI '12), 2589-2598. https://doi.org/10.1145/2207676.2208649

40. Leah Findlater, Jon E. Froehlich, Kays Fattal, Jacob O. Wobbrock, and Tanya Dastyar. 2013. Age-related differences in performance with touchscreens compared to traditional mouse input. In Proceedings of the SIGCHI Conference on Human Factors in Computing Systems (CHI '13), 343-346. https://doi.org/10.1145/2470654.2470703

41. David R. Flatla, Alan R. Andrade, Ross D. Teviotdale, Dylan L. Knowles, and Craig Stewart. 2015. ColourID: Improving Colour Identification for People with Impaired Colour Vision. In Proceedings of the 33rd Annual ACM Conference on Human Factors in Computing Systems (CHI '15), 3543-3552. https://doi.org/10.1145/2702123.2702578

42. Germán H. Flores and Roberto Manduchi. 2018. WeAllWalk: An Annotated Dataset of Inertial Sensor Time Series from Blind Walkers. ACM Transactions on Accessible Computing 11, 1: 4:1-4:28. https://doi.org/10.1145/3161711

43. Raymond Fok, Harmanpreet Kaur, Skanda Palani, Martez E. Mott, and Walter S. Lasecki. 2018. Towards More Robust Speech Interactions for Deaf and Hard of Hearing Users. In Proceedings of the 20th International ACM SIGACCESS Conference on Computers and Accessibility (ASSETS '18), 57-67. https://doi.org/10.1145/3234695.3236343

44. Christopher Frauenberger. 2015. Disability and Technology: A Critical Realist Perspective. In Proceedings of the 17th International ACM SIGACCESS Conference on Computers \& Accessibility (ASSETS '15), 89-96. https://doi.org/10.1145/2700648.2809851

45. Christopher Frauenberger, Julia Makhaeva, and Katta Spiel. 2017. Blending Methods: Developing Participatory Design Sessions for Autistic Children. In Proceedings of the 2017 Conference on Interaction Design and Children (IDC '17), 39-49. https://doi.org/10.1145/3078072.3079727

46. Christopher Frauenberger, Julia Makhaeva, and Katta Spiel. 2017. Interaction Design and Autistic Children. In Proceedings of the 2017 Conference on Interaction Design and Children (IDC '17), 743-748. https://doi.org/10.1145/3078072.3081309 
47. Euan Freeman, Graham Wilson, Stephen Brewster, Gabriel Baud-Bovy, Charlotte Magnusson, and Hector Caltenco. 2017. Audible Beacons and Wearables in Schools: Helping Young Visually Impaired Children Play and Move Independently. In Proceedings of the 2017 CHI Conference on Human Factors in Computing Systems (CHI '17), 4146-4157. https://doi.org/10.1145/3025453.3025518

48. Kathrin Maria Gerling, Regan L. Mandryk, Max Valentin Birk, Matthew Miller, and Rita Orji. 2014. The effects of embodied persuasive games on player attitudes toward people using wheelchairs. In Proceedings of the SIGCHI Conference on Human Factors in Computing Systems (CHI'14), 3413-3422. https://doi.org/10.1145/2556288.2556962

49. Emilie Giles, Janet van der Linden, and Marian Petre. 2018. Weaving Lighthouses and Stitching Stories: Blind and Visually Impaired People Designing E-textiles. In Proceedings of the 2018 CHI Conference on Human Factors in Computing Systems (CHI '18), 1-12. https://doi.org/10.1145/3173574.3174044

50. Ephraim P Glinert and Bryant W York. 1992. Computers and People with Disabilities. Commun. ACM 35, 5: 32-35. https://doi.org/10.1145/129875.129876

51. Benjamin M. Gorman and David R. Flatla. 2017. A Framework for Speechreading Acquisition Tools. In Proceedings of the 2017 CHI Conference on Human Factors in Computing Systems (CHI '17), 519-530. https://doi.org/10.1145/3025453.3025560

52. William Grussenmeyer and Eelke Folmer. 2017. Accessible Touchscreen Technology for People with Visual Impairments: A Survey. ACM Trans. Access. Comput. 9, 2. https://doi.org/10.1145/3022701

53. Foad Hamidi, Melanie Baljko, and Isabel Gómez. 2017. Using Participatory Design with Proxies with Children with Limited Communication. In Proceedings of the 19th International ACM SIGACCESS Conference on Computers and Accessibility (ASSETS '17), 250-259. https://doi.org/10.1145/3132525.3132527

54. Christina N. Harrington, Katya Borgos-Rodriguez, and Anne Marie Piper. 2019. Engaging Low-Income African American Older Adults in Health Discussions through Community-based Design Workshops. In Proceedings of the 2019 CHI Conference on Human Factors in Computing Systems (CHI '19), 1-15. https://doi.org/10.1145/3290605.3300823

55. Hamilton A. Hernandez, Zi Ye, T.C. Nicholas Graham, Darcy Fehlings, and Lauren Switzer. 2013. Designing action-based exergames for children with cerebral palsy. In Proceedings of the SIGCHI Conference on Human Factors in Computing Systems (CHI '13), 1261-1270. https://doi.org/10.1145/2470654.2466164

56. Ellen S. Hibbard and Deb I. Fels. 2011. The vlogging phenomena: a deaf perspective. In The proceedings of the 13th international ACM SIGACCESS conference on Computers and accessibility (ASSETS '11), 59-66. https://doi.org/10.1145/2049536.2049549

57. Sen H. Hirano, Michael T. Yeganyan, Gabriela Marcu, David H. Nguyen, Lou Anne Boyd, and Gillian R. Hayes. 2010. vSked: evaluation of a system to support classroom activities for children with autism. In Proceedings of the SIGCHI Conference on Human Factors in Computing Systems (CHI '10), 1633-1642. https://doi.org/10.1145/1753326.1753569

58. Megan Hofmann, Devva Kasnitz, Jennifer Mankoff, and Cynthia L Bennett. 2020. Living Disability Theory: Reflections on Access, Research, and Design. In The 22nd International ACM SIGACCESS Conference on Computers and Accessibility (ASSETS '20), 1-13. https://doi.org/10.1145/3373625.3416996

59. Megan Hofmann, Kristin Williams, Toni Kaplan, Stephanie Valencia, Gabriella Hann, Scott E. Hudson, Jennifer Mankoff, and Patrick Carrington. 2019. “Occupational Therapy is Making”: Clinical Rapid Prototyping and Digital Fabrication. In Proceedings of the 2019 CHI Conference on Human Factors in Computing Systems (CHI '19), 1-13. https://doi.org/10.1145/3290605.3300544

60. Nic Hollinworth and Faustina Hwang. 2010. Relating computer tasks to existing knowledge to improve accessibility for older adults. In Proceedings of the 12th international ACM SIGACCESS conference on Computers and accessibility (ASSETS '10), 147-154. https://doi.org/10.1145/1878803.1878830

61. Leona Holloway, Kim Marriott, Matthew Butler, and Samuel Reinders. 2019. 3D Printed Maps and Icons for Inclusion: Testing in the Wild by People who are Blind or have Low Vision. In The 21st International ACM SIGACCESS Conference on Computers and Accessibility (ASSETS '19), 183-195. https://doi.org/10.1145/3308561.3353790

62. Harald Holone and Jo Herstad. 2013. Three tensions in participatory design for inclusion. In Proceedings of the SIGCHI Conference on Human Factors in Computing Systems (CHI '13), 2903-2906. https://doi.org/10.1145/2470654.2481401 
63. Kasper Hornbæk, Aske Mottelson, Jarrod Knibbe, and Daniel Vogel. 2019. What Do We Mean by "Interaction"? An Analysis of 35 Years of CHI. ACM Transactions on Computer-Human Interaction 26, 4: 27:127:30. https://doi.org/10.1145/3325285

64. Anthony Hornof, Haley Whitman, Marah Sutherland, Samuel Gerendasy, and Joanna McGrenere. 2017. Designing for the "Universe of One": Personalized Interactive Media Systems for People with the Severe Cognitive Impairment Associated with Rett Syndrome. In Proceedings of the 2017 CHI Conference on Human Factors in Computing Systems (CHI '17), 2137-2148. https://doi.org/10.1145/3025453.3025904

65. Matt Huenerfauth, Pengfei Lu, and Andrew Rosenberg. 2011. Evaluating importance of facial expression in american sign language and pidgin signed english animations. In The proceedings of the 13th international ACM SIGACCESS conference on Computers and accessibility (ASSETS '11), 99-106. https://doi.org/10.1145/2049536.2049556

66. Matt Huenerfauth, Kasmira Patel, and Larwan Berke. 2017. Design and Psychometric Evaluation of an American Sign Language Translation of the System Usability Scale. In Proceedings of the 19th International ACM SIGACCESS Conference on Computers and Accessibility (ASSETS '17), 175-184. https://doi.org/10.1145/3132525.3132540

67. Earl W. Huff, Natalie DellaMaria, Brianna Posadas, and Julian Brinkley. 2019. Am I Too Old to Drive? Opinions of Older Adults on Self-Driving Vehicles. In The 21st International ACM SIGACCESS Conference on Computers and Accessibility (ASSETS '19), 500-509. https://doi.org/10.1145/3308561.3353801

68. Dhruv Jain, Audrey Desjardins, Leah Findlater, and Jon E. Froehlich. 2019. Autoethnography of a Hard of Hearing Traveler. In The 21st International ACM SIGACCESS Conference on Computers and Accessibility (ASSETS '19), 236-248. https://doi.org/10.1145/3308561.3353800

69. Matthew Jamieson, Brian O'Neill, Breda Cullen, Marilyn Lennon, Stephen Brewster, and Jonathan Evans. 2017. ForgetMeNot: Active Reminder Entry Support for Adults with Acquired Brain Injury. In Proceedings of the 2017 CHI Conference on Human Factors in Computing Systems (CHI '17), 6012-6023. https://doi.org/10.1145/3025453.3025888

70. Hernisa Kacorri, Kris M. Kitani, Jeffrey P. Bigham, and Chieko Asakawa. 2017. People with Visual Impairment Training Personal Object Recognizers: Feasibility and Challenges. In Proceedings of the 2017 CHI Conference on Human Factors in Computing Systems (CHI '17), 5839-5849. https://doi.org/10.1145/3025453.3025899

71. Alison Kafer. 2013. Feminist, Queer, Crip. Indiana University Press.

72. Yoram M. Kalman, Kathleen Geraghty, Cynthia K. Thompson, and Darren Gergle. 2012. Detecting linguistic HCI markers in an online aphasia support group. In Proceedings of the 14th international ACM SIGACCESS conference on Computers and accessibility (ASSETS '12), 65-70. https://doi.org/10.1145/2384916.2384928

73. Shaun K. Kane, Barbara Linam-Church, Kyle Althoff, and Denise McCall. 2012. What we talk about: designing a context-aware communication tool for people with aphasia. In Proceedings of the 14th international ACM SIGACCESS conference on Computers and accessibility (ASSETS '12), 49-56. https://doi.org/10.1145/2384916.2384926

74. Shaun K. Kane, Meredith Ringel Morris, Ann Paradiso, and Jon Campbell. 2017. "At times avuncular and cantankerous, with the reflexes of a mongoose": Understanding Self-Expression through Augmentative and Alternative Communication Devices. In Proceedings of the 2017 ACM Conference on Computer Supported Cooperative Work and Social Computing (CSCW '17), 1166-1179. https://doi.org/10.1145/2998181.2998284

75. Shaun K. Kane, Jacob O. Wobbrock, and Richard E. Ladner. 2011. Usable gestures for blind people: understanding preference and performance. In Proceedings of the SIGCHI Conference on Human Factors in Computing Systems (CHI '11), 413-422. https://doi.org/10.1145/1978942.1979001

76. Devva Kasnitz and Russell Shuttleworth. 2001. Introduction: Anthropology in Disability Studies. Disability Studies Quarterly 21, 3.

77. Edward Kim and Kathleen F. McCoy. 2018. Multimodal Deep Learning using Images and Text for Information Graphic Classification. In Proceedings of the 20th International ACM SIGACCESS Conference on Computers and Accessibility (ASSETS '18), 143-148. https://doi.org/10.1145/3234695.3236357

78. Michael Kipp, Quan Nguyen, Alexis Heloir, and Silke Matthes. 2011. Assessing the deaf user perspective on sign language avatars. In The proceedings of the 13th international ACM SIGACCESS conference on Computers and accessibility (ASSETS '11), 107-114. https://doi.org/10.1145/2049536.2049557 
79. Bran Knowles, Vicki L Hanson, Yvonne Rogers, Anne Marie Piper, Jenny Waycott, Nigel Davies, Aloha Ambe, Robin N Brewer, Debaleena Chattopadhyay, Marianne Dee, David Frohlich, Marisela Gutierrez-Lopez, Ben Jelen, Amanda Lazar, Radoslaw Nielek, Belen Barros Pena, Abi Roper, Mark Schlager, Britta Schulte, and Irene Ye Yuan. 2020. The Harm in Conflating Aging with Accessibility. Communications of the Association for Information Systems.

80. Lisa Koeman. 2020. HCI/UX Research: What Methods Do We Use? Retrieved August 8, 2020 from https://lisakoeman.nl/blog/hci-ux-research-what-methods-do-we-use/

81. Sri H. Kurniawan, Sonia Arteaga, and Roberto Manduchi. 2010. A general education course on universal access, disability, technology and society. In Proceedings of the 12th international ACM SIGACCESS conference on Computers and accessibility (ASSETS '10), 11-18. https://doi.org/10.1145/1878803.1878808

82. Raja S. Kushalnagar, Gary W. Behm, Aaron W. Kelstone, and Shareef Ali. 2015. Tracked Speech-To-Text Display: Enhancing Accessibility and Readability of Real-Time Speech-To-Text. In Proceedings of the 17th International ACM SIGACCESS Conference on Computers \& Accessibility (ASSETS '15), 223-230. https://doi.org/10.1145/2700648.2809843

83. Raja S. Kushalnagar, Walter S. Lasecki, and Jeffrey P. Bigham. 2012. A readability evaluation of real-time crowd captions in the classroom. In Proceedings of the 14th international ACM SIGACCESS conference on Computers and accessibility (ASSETS '12), 71-78. https://doi.org/10.1145/2384916.2384930

84. R E Ladner, F A McDonough, W Roth, L A Scadden, and G C Vanderheiden. 1988. Public Law 99-506, "Section 508" Electronic Equipment Accessibility for Disabled Workers. In Proceedings of the SIGCHI Conference on Human Factors in Computing Systems (CHI '88), 219-222. https://doi.org/10.1145/57167.57204

85. Amanda Lazar, Caroline Edasis, and Anne Marie Piper. 2017. A Critical Lens on Dementia and Design in HCI. In Proceedings of the 2017 CHI Conference on Human Factors in Computing Systems (CHI '17), 2175-2188. https://doi.org/10.1145/3025453.3025522

86. Jonathan Lazar. 2019. Web Accessibility Policy and Law. In Web Accessibility. Springer, 247-261.

87. Jonathan Lazar, Daniel F. Goldstein, and Anne Taylor. 2015. Introduction to Accessible Technology. In Ensuring Digital Accessibility through Process and Policy. Morgan Kaufmann.

88. Jonathan Lazar, Daniel Goldstein, and Anne Taylor. 2015. Ensuring Digital Accessibility through Process and Policy.

89. Zuzanna Lechelt, Yvonne Rogers, Nicola Yuill, Lena Nagl, Grazia Ragone, and Nicolai Marquardt. 2018. Inclusive Computing in Special Needs Classrooms: Designing for All. In Proceedings of the $2018 \mathrm{CHI}$ Conference on Human Factors in Computing Systems (CHI '18), 1-12. https://doi.org/10.1145/3173574.3174091

90. Kyungjun Lee and Hernisa Kacorri. 2019. Hands Holding Clues for Object Recognition in Teachable Machines. In Proceedings of the 2019 CHI Conference on Human Factors in Computing Systems (CHI '19), 1-12. https://doi.org/10.1145/3290605.3300566

91. Hanlin Li, Disha Bora, Sagar Salvi, and Erin Brady. 2018. Slacktivists or Activists? Identity Work in the Virtual Disability March. In Proceedings of the 2018 CHI Conference on Human Factors in Computing Systems (CHI '18), 1-13. https://doi.org/10.1145/3173574.3173799

92. Qisheng Li, Krzysztof Z. Gajos, and Katharina Reinecke. 2018. Volunteer-Based Online Studies With Older Adults and People with Disabilities. In Proceedings of the 20th International ACM SIGACCESS Conference on Computers and Accessibility (ASSETS '18), 229-241. https://doi.org/10.1145/3234695.3236360

93. Yong Liu, Jorge Goncalves, Denzil Ferreira, Bei Xiao, Simo Hosio, and Vassilis Kostakos. 2014. CHI 1994-2013: mapping two decades of intellectual progress through co-word analysis. In Proceedings of the SIGCHI Conference on Human Factors in Computing Systems (CHI '14), 3553-3562. https://doi.org/10.1145/2556288.2556969

94. Elizabeth R. Lorah, Ashley Parnell, Peggy Schaefer Whitby, and Donald Hantula. 2015. A Systematic Review of Tablet Computers and Portable Media Players as Speech Generating Devices for Individuals with Autism Spectrum Disorder. Journal of Autism and Developmental Disorders 45, 12: 3792-3804. https://doi.org/10.1007/s10803-014-2314-4

95. Ewa Luger, Stuart Moran, and Tom Rodden. 2013. Consent for all: revealing the hidden complexity of terms and conditions. In Proceedings of the SIGCHI Conference on Human Factors in Computing Systems (CHI '13), 2687-2696. https://doi.org/10.1145/2470654.2481371 
96. Rhouri MacAlpine and David R. Flatla. 2016. Real-Time Mobile Personalized Simulations of Impaired Colour Vision. In Proceedings of the 18th International ACM SIGACCESS Conference on Computers and Accessibility (ASSETS '16), 181-189. https://doi.org/10.1145/2982142.2982170

97. Galina Madjaroff and Helena Mentis. 2017. Narratives of Older Adults with Mild Cognitive Impairment and Their Caregivers. In Proceedings of the 19th International ACM SIGACCESS Conference on Computers and Accessibility (ASSETS '17), 140-149. https://doi.org/10.1145/3132525.3132554

98. Meethu Malu, Pramod Chundury, and Leah Findlater. 2018. Exploring Accessible Smartwatch Interactions for People with Upper Body Motor Impairments. In Proceedings of the 2018 CHI Conference on Human Factors in Computing Systems (CHI '18), 1-12. https://doi.org/10.1145/3173574.3174062

99. Jennifer Mankoff, Gillian R Hayes, and Devva Kasnitz. 2010. Disability Studies as a Source of Critical Inquiry for the Field of Assistive Technology. In Proceedings of the 12th International ACM SIGACCESS Conference on Computers and Accessibility (ASSETS '10), 3-10. https://doi.org/10.1145/1878803.1878807

100. Jennifer Mankoff, Gillian R. Hayes, and Devva Kasnitz. 2010. Disability studies as a source of critical inquiry for the field of assistive technology. In Proceedings of the 12th international ACM SIGACCESS conference on Computers and accessibility (ASSETS '10), 3-10. https://doi.org/10.1145/1878803.1878807

101. Roisin McNaney, Stephen Lindsay, Karim Ladha, Cassim Ladha, Guy Schofield, Thomas Ploetz, Nils Hammerla, Daniel Jackson, Richard Walker, Nick Miller, and Patrick Olivier. 2011. Cueing for drooling in Parkinson's disease. In Proceedings of the SIGCHI Conference on Human Factors in Computing Systems (CHI '11), 619-622. https://doi.org/10.1145/1978942.1979030

102. Chao Mei, Lee Mason, and John Quarles. 2014. Usability issues with 3D user interfaces for adolescents with high functioning autism. In Proceedings of the 16th international ACM SIGACCESS conference on Computers \& accessibility (ASSETS '14), 99-106. https://doi.org/10.1145/2661334.2661379

103. Helena M. Mentis, Galina Madjaroff, and Aaron K. Massey. 2019. Upside and Downside Risk in Online Security for Older Adults with Mild Cognitive Impairment. In Proceedings of the 2019 CHI Conference on Human Factors in Computing Systems (CHI '19), 1-13. https://doi.org/10.1145/3290605.3300573

104. Oussama Metatla and Clare Cullen. 2018. "Bursting the Assistance Bubble": Designing Inclusive Technology with Children with Mixed Visual Abilities. In Proceedings of the 2018 CHI Conference on Human Factors in Computing Systems (CHI '18), 1-14. https://doi.org/10.1145/3173574.3173920

105. Johanna Meurer, Martin Stein, David Randall, Markus Rohde, and Volker Wulf. 2014. Social dependency and mobile autonomy: supporting older adults' mobility with ridesharing ict. In Proceedings of the SIGCHI Conference on Human Factors in Computing Systems (CHI '14), 1923-1932. https://doi.org/10.1145/2556288.2557300

106. Silvia Mirri, Ludovico Antonio Muratori, and Paola Salomoni. 2011. Monitoring accessibility: large scale evaluations at a Geo political level. In The proceedings of the 13th international ACM SIGACCESS conference on Computers and accessibility (ASSETS '11), 163-170. https://doi.org/10.1145/2049536.2049566

107. Lourdes M. Morales-Villaverde, Karina Caro, Taylor Gotfrid, and Sri Kurniawan. 2016. Online Learning System to Help People with Developmental Disabilities Reinforce Basic Skills. In Proceedings of the 18th International ACM SIGACCESS Conference on Computers and Accessibility (ASSETS '16), 43-51. https://doi.org/10.1145/2982142.2982174

108. Meredith Ringel Morris, Andrew Begel, and Ben Wiedermann. 2015. Understanding the Challenges Faced by Neurodiverse Software Engineering Employees: Towards a More Inclusive and Productive Technical Workforce. In Proceedings of the 17th International ACM SIGACCESS Conference on Computers \& Accessibility (ASSETS '15), 173-184. https://doi.org/10.1145/2700648.2809841

109. Robert R. Morris, Connor R. Kirschbaum, and Rosalind W. Picard. 2010. Broadening accessibility through special interests: a new approach for software customization. In Proceedings of the 12th international ACM SIGACCESS conference on Computers and accessibility (ASSETS '10), 171-178. https://doi.org/10.1145/1878803.1878834

110. Martez E. Mott, Radu-Daniel Vatavu, Shaun K. Kane, and Jacob O. Wobbrock. 2016. Smart Touch: Improving Touch Accuracy for People with Motor Impairments with Template Matching. In Proceedings of the 2016 CHI Conference on Human Factors in Computing Systems (CHI '16), 1934-1946. https://doi.org/10.1145/2858036.2858390

111. Michael J. Muller and Sarah Kuhn. 1993. Participatory design. Communications of the ACM 36, 6: 24-28. https://doi.org/10.1145/153571.255960 
112. Lorene M. Nelson, W. T. Longstreth, Thomas D. Koepsell, and Gerald Van Belle. 1990. PROXY RESPONDENTS IN EPIDEMIOLOGIC RESEARCH. Epidemiologic Reviews 12, 1: 71-86. https://doi.org/10.1093/oxfordjournals.epirev.a036063

113. Hugo Nicolau and Joaquim Jorge. 2012. Elderly text-entry performance on touchscreens. In Proceedings of the 14th international ACM SIGACCESS conference on Computers and accessibility (ASSETS '12), 127-134. https://doi.org/10.1145/2384916.2384939

114. Hugo Nicolau, Kyle Montague, Tiago Guerreiro, André Rodrigues, and Vicki L. Hanson. 2015. Typing Performance of Blind Users: An Analysis of Touch Behaviors, Learning Effect, and In-Situ Usage. In Proceedings of the 17th International ACM SIGACCESS Conference on Computers \& Accessibility (ASSETS '15), 273-280. https://doi.org/10.1145/2700648.2809861

115. Hugo Nicolau, André Rodrigues, André Santos, Tiago Guerreiro, Kyle Montague, and João Guerreiro. 2019. The Design Space of Nonvisual Word Completion. In The 21st International ACM SIGACCESS Conference on Computers and Accessibility (ASSETS '19), 249-261. https://doi.org/10.1145/3308561.3353786

116. Sonya Nikolova, Marilyn Tremaine, and Perry R. Cook. 2010. Click on bake to get cookies: guiding wordfinding with semantic associations. In Proceedings of the 12th international ACM SIGACCESS conference on Computers and accessibility (ASSETS '10), 155-162. https://doi.org/10.1145/1878803.1878832

117. Ihudiya Finda Ogbonnaya-Ogburu, Angela D.R. Smith, Alexandra To, and Kentaro Toyama. 2020. Critical Race Theory for HCI. In Proceedings of the 2020 CHI Conference on Human Factors in Computing Systems (CHI '20), 1-16. https://doi.org/10.1145/3313831.3376392

118. Uran Oh, Lee Stearns, Alisha Pradhan, Jon E. Froehlich, and Leah Findlater. 2017. Investigating Microinteractions for People with Visual Impairments and the Potential Role of On-Body Interaction. In Proceedings of the 19th International ACM SIGACCESS Conference on Computers and Accessibility (ASSETS '17), 22-31. https://doi.org/10.1145/3132525.3132536

119. Yi-Hao Peng, Ming-Wei Hsi, Paul Taele, Ting-Yu Lin, Po-En Lai, Leon Hsu, Tzu-chuan Chen, Te-Yen Wu, Yu-An Chen, Hsien-Hui Tang, and Mike Y. Chen. 2018. SpeechBubbles: Enhancing Captioning Experiences for Deaf and Hard-of-Hearing People in Group Conversations. In Proceedings of the 2018 CHI Conference on Human Factors in Computing Systems (CHI '18), 1-10. https://doi.org/10.1145/3173574.3173867

120. Paola Pennisi, Alessandro Tonacci, Gennaro Tartarisco, Lucia Billeci, Liliana Ruta, Sebastiano Gangemi, and Giovanni Pioggia. 2016. Autism and social robotics: A systematic review. Autism Research 9, 165-183. https://doi.org/10.1002/aur.1527

121. Hans Persson, Henrik Åhman, Alexander Arvei Yngling, and Jan Gulliksen. 2015. Universal design, inclusive design, accessible design, design for all: different concepts-one goal? On the concept of accessibilityhistorical, methodological and philosophical aspects. Universal Access in the Information Society 14, 4: 505526. https://doi.org/10.1007/s10209-014-0358-z

122. Halley P. Profita, Abigale Stangl, Laura Matuszewska, Sigrunn Sky, and Shaun K. Kane. 2016. Nothing to Hide: Aesthetic Customization of Hearing Aids and Cochlear Implants in an Online Community. In Proceedings of the 18th International ACM SIGACCESS Conference on Computers and Accessibility (ASSETS '16), 219-227. https://doi.org/10.1145/2982142.2982159

123. Cynthia Putnam, Kathryn Wozniak, Mary Jo Zefeldt, Jinghui Cheng, Morgan Caputo, and Carl Duffield. 2012. How do professionals who create computing technologies consider accessibility? In Proceedings of the 14th international ACM SIGACCESS conference on Computers and accessibility (ASSETS '12), 87-94. https://doi.org/10.1145/2384916.2384932

124. Chengcheng Qu, Corina Sas, and Gavin Doherty. 2019. Exploring and Designing for Memory Impairments in Depression. In Proceedings of the 2019 CHI Conference on Human Factors in Computing Systems (CHI '19), 115. https://doi.org/10.1145/3290605.3300740

125. Laura Ramos, Elise van den Hoven, and Laurie Miller. 2016. Designing for the Other "Hereafter": When Older Adults Remember about Forgetting. In Proceedings of the 2016 CHI Conference on Human Factors in Computing Systems (CHI '16), 721-732. https://doi.org/10.1145/2858036.2858162

126. Luz Rello and Jeffrey P. Bigham. 2017. Good Background Colors for Readers: A Study of People with and without Dyslexia. In Proceedings of the 19th International ACM SIGACCESS Conference on Computers and Accessibility (ASSETS '17), 72-80. https://doi.org/10.1145/3132525.3132546

127. Kathryn E. Ringland, Jennifer Nicholas, Rachel Kornfield, Emily G. Lattie, David C. Mohr, and Madhu Reddy. 2019. Understanding Mental Ill-health as Psychosocial Disability: Implications for Assistive Technology. In 
The 21st International ACM SIGACCESS Conference on Computers and Accessibility (ASSETS '19), 156-170. https://doi.org/10.1145/3308561.3353785

128. Kathryn E. Ringland, Christine T. Wolf, LouAnne E. Boyd, Mark S. Baldwin, and Gillian R. Hayes. 2016. Would You Be Mine: Appropriating Minecraft as an Assistive Technology for Youth with Autism. In Proceedings of the 18th International ACM SIGACCESS Conference on Computers and Accessibility (ASSETS '16), 33-41. https://doi.org/10.1145/2982142.2982172

129. Frederico da Rocha Tomé Filho, Pejman Mirza-Babaei, Bill Kapralos, and Glaudiney Moreira Mendonça Junior. 2019. Let's Play Together: Adaptation Guidelines of Board Games for Players with Visual Impairment. In Proceedings of the 2019 CHI Conference on Human Factors in Computing Systems (CHI '19), 1-15. https://doi.org/10.1145/3290605.3300861

130. Jim Rowan and Elizabeth D. Mynatt. 2005. Digital Family Portrait Field Trial: Support for Aging in Place. In Proceedings of the SIGCHI Conference on Human Factors in Computing Systems (CHI '05), 521-530. https://doi.org/10.1145/1054972.1055044

131. Ana-Maria Salai and Lynne Baillie. 2019. A Wee Bit More Interaction: Designing and Evaluating an Overactive Bladder App. In Proceedings of the 2019 CHI Conference on Human Factors in Computing Systems (CHI '19), 114. https://doi.org/10.1145/3290605.3300933

132. Andrew Sears and Vicki Hanson. 2011. Representing users in accessibility research. In Proceedings of the SIGCHI Conference on Human Factors in Computing Systems (CHI '11), 2235-2238. https://doi.org/10.1145/1978942.1979268

133. Tom Shakespeare. 2010. The Social Model of Disability. In The Disability Studies Reader, Lennard J. Davis (ed.). Routledge, New York, 266-273.

134. Joseph P. Shapiro. 2011. No Pity: People with Disabilities Forging a New Civil Rights Movement. Crown.

135. Kristen Shinohara and Jacob O. Wobbrock. 2011. In the shadow of misperception: assistive technology use and social interactions. In Proceedings of the SIGCHI Conference on Human Factors in Computing Systems (CHI '11), 705-714. https://doi.org/10.1145/1978942.1979044

136. Tobin Sieber. 2008. Disability Theory.

137. Laurianne Sitbon, Ross Brown, and Lauren Fell. 2019. Turning Heads: Designing Engaging Immersive Video Experiences to Support People with Intellectual Disability when Learning Everyday Living Skills. In The 21st International ACM SIGACCESS Conference on Computers and Accessibility (ASSETS '19), 171-182. https://doi.org/10.1145/3308561.3353787

138. Kiley Sobel, Kyle Rector, Susan Evans, and Julie A. Kientz. 2016. Incloodle: Evaluating an Interactive Application for Young Children with Mixed Abilities. In Proceedings of the 2016 CHI Conference on Human Factors in Computing Systems (CHI '16), 165-176. https://doi.org/10.1145/2858036.2858114

139. Tobias Sonne, Jörg Müller, Paul Marshall, Carsten Obel, and Kaj Grønbæk. 2016. Changing Family Practices with Assistive Technology: MOBERO Improves Morning and Bedtime Routines for Children with ADHD. In Proceedings of the 2016 CHI Conference on Human Factors in Computing Systems (CHI '16), 152-164. https://doi.org/10.1145/2858036.2858157

140. Katta Spiel, Christopher Frauenberger, Os Keyes, and Geraldine Fitzpatrick. 2019. Agency of Autistic Children in Technology Research-A Critical Literature Review. ACM Trans. Comput.-Hum. Interact. 26, 6. https://doi.org/10.1145/3344919

141. Katta Spiel, Kathrin Gerling, Cynthia L Bennett, Emeline Brulé, Rua M Williams, Jennifer Rode, and Jennifer Mankoff. 2020. Nothing About Us Without Us: Investigating the Role of Critical Disability Studies in HCI. In Extended Abstracts of the 2020 CHI Conference on Human Factors in Computing Systems (CHI EA '20), 1-8. https://doi.org/10.1145/3334480.3375150

142. Abigale Stangl, Ann Cunningham, Lou Ann Blake, and Tom Yeh. 2019. Defining Problems of Practices to Advance Inclusive Tactile Media Consumption and Production. In The 21st International ACM SIGACCESS Conference on Computers and Accessibility (ASSETS '19), 329-341. https://doi.org/10.1145/3308561.3353778

143. Sarit Felicia Anais Szpiro, Shafeka Hashash, Yuhang Zhao, and Shiri Azenkot. 2016. How People with Low Vision Access Computing Devices: Understanding Challenges and Opportunities. In Proceedings of the 18th International ACM SIGACCESS Conference on Computers and Accessibility (ASSETS '16), 171-180. https://doi.org/10.1145/2982142.2982168 
144. Anja Thieme, Jayne Wallace, Paula Johnson, John McCarthy, Siân Lindley, Peter Wright, Patrick Olivier, and Thomas D. Meyer. 2013. Design to promote mindfulness practice and sense of self for vulnerable women in secure hospital services. In Proceedings of the SIGCHI Conference on Human Factors in Computing Systems (CHI '13), 2647-2656. https://doi.org/10.1145/2470654.2481366

145. Jessica J. Tran, Joy Kim, Jaehong Chon, Eve A. Riskin, Richard E. Ladner, and Jacob O. Wobbrock. 2011. Evaluating quality and comprehension of real-time sign language video on mobile phones. In The proceedings of the 13th international ACM SIGACCESS conference on Computers and accessibility (ASSETS '11), 115-122. https://doi.org/10.1145/2049536.2049558

146. Shari Trewin, Bonnie E. John, John Richards, Cal Swart, Jonathan Brezin, Rachel Bellamy, and John Thomas. 2010. Towards a tool for keystroke level modeling of skilled screen reading. In Proceedings of the 12th international ACM SIGACCESS conference on Computers and accessibility (ASSETS '10), 27-34. https://doi.org/10.1145/1878803.1878811

147. Shari Trewin, Diogo Marques, and Tiago Guerreiro. 2015. Usage of Subjective Scales in Accessibility Research. In Proceedings of the 17th International ACM SIGACCESS Conference on Computers \& Accessibility (ASSETS '15), 59-67. https://doi.org/10.1145/2700648.2809867

148. Shari Trewin, Meredith Ringel Morris, Stacy Branham, Walter S. Lasecki, Shiri Azenkot, Nicole Bleuel, Shiri Azenkot, Phill Jenkins, and Jeffrey P. Bigham. 2020. Workshop on AI fairness for people with disabilities. ACM SIGACCESS Accessibility and Computing, 125: 1:1. https://doi.org/10.1145/3386296.3386297

149. Shari Trewin, John T. Richards, Vicki L. Hanson, David Sloan, Bonnie E. John, Cal Swart, and John C. Thomas. 2012. Understanding the role of age and fluid intelligence in information search. In Proceedings of the 14th international ACM SIGACCESS conference on Computers and accessibility (ASSETS '12), 119-126. https://doi.org/10.1145/2384916.2384938

150. Radu-Daniel Vatavu and Ovidiu-Ciprian Ungurean. 2019. Stroke-Gesture Input for People with Motor Impairments: Empirical Results \& Research Roadmap. In Proceedings of the 2019 CHI Conference on Human Factors in Computing Systems (CHI '19), 1-14. https://doi.org/10.1145/3290605.3300445

151. John Vines, Gary Pritchard, Peter Wright, Patrick Olivier, and Katie Brittain. 2015. An Age-Old Problem: Examining the Discourses of Ageing in HCI and Strategies for Future Research. ACM Trans. Comput.-Hum. Interact. 22, 1. https://doi.org/10.1145/2696867

152. Pooja Viswanathan, James J. Little, Alan K. Mackworth, and Alex Mihailidis. 2011. Navigation and obstacle avoidance help (NOAH) for older adults with cognitive impairment: a pilot study. In The proceedings of the 13th international ACM SIGACCESS conference on Computers and accessibility (ASSETS '11), 43-50. https://doi.org/10.1145/2049536.2049546

153. Chat Wacharamanotham, Jan Hurtmanns, Alexander Mertens, Martin Kronenbuerger, Christopher Schlick, and Jan Borchers. 2011. Evaluating swabbing: a touchscreen input method for elderly users with tremor. In Proceedings of the SIGCHI Conference on Human Factors in Computing Systems (CHI '11), 623-626. https://doi.org/10.1145/1978942.1979031

154. Jonathan Waddington, Conor Linehan, Kathrin Gerling, Kieran Hicks, and Timothy L. Hodgson. 2015. Participatory Design of Therapeutic Video Games for Young People with Neurological Vision Impairment. In Proceedings of the 33rd Annual ACM Conference on Human Factors in Computing Systems (CHI '15), 35333542. https://doi.org/10.1145/2702123.2702261

155. Rua M Williams and LouAnne E Boyd. 2019. Prefigurative Politics and Passionate Witnessing. In The 21st International ACM SIGACCESS Conference on Computers and Accessibility, 262-266.

156. Rua M. Williams and Juan E. Gilbert. 2020. Perseverations of the academy: A survey of wearable technologies applied to autism intervention. International Journal of Human-Computer Studies 143: 102485. https://doi.org/10.1016/j.ijhcs.2020.102485

157. Cara Wilson, Margot Brereton, Bernd Ploderer, Laurianne Sitbon, and Beth Saggers. 2017. Digital Strategies for Supporting Strengths- and Interests-based Learning with Children with Autism. In Proceedings of the 19th International ACM SIGACCESS Conference on Computers and Accessibility (ASSETS '17), 52-61. https://doi.org/10.1145/3132525.3132553

158. Jacob O. Wobbrock, Shaun K. Kane, Krzysztof Z. Gajos, Susumu Harada, and Jon Froehlich. 2011. Ability-Based Design: Concept, Principles and Examples. ACM Transactions on Accessible Computing 3, 3: 1-27. https://doi.org/10.1145/1952383.1952384 
159. Jacob O. Wobbrock and Julie A. Kientz. 2016. Research contribution in human-computer interaction. interactions 23, 3: 38-44. https://doi.org/10.1145/2907069

160. Maria K. Wolters, Jonathan Kilgour, Sarah E. MacPherson, Myroslava Dzikovska, and Johanna D. Moore. 2015. The CADENCE Corpus: A New Resource for Inclusive Voice Interface Design. In Proceedings of the 33rd Annual ACM Conference on Human Factors in Computing Systems (CHI '15), 3963-3966. https://doi.org/10.1145/2702123.2702372

161. Mike Wu, Ronald M. Baecker, and Brian Richards. 2010. Field evaluation of a collaborative memory aid for persons with amnesia and their family members. In Proceedings of the 12th international ACM SIGACCESS conference on Computers and accessibility (ASSETS '10), 51-58. https://doi.org/10.1145/1878803.1878815

162. Shaomei Wu, Lindsay Reynolds, Xian Li, and Francisco Guzmán. 2019. Design and Evaluation of a Social Media Writing Support Tool for People with Dyslexia. In Proceedings of the 2019 CHI Conference on Human Factors in Computing Systems (CHI '19), 1-14. https://doi.org/10.1145/3290605.3300746

163. Naomi Yamashita, Hideaki Kuzuoka, Keiji Hirata, and Takashi Kudo. 2013. Understanding the conflicting demands of family caregivers caring for depressed family members. In Proceedings of the SIGCHI Conference on Human Factors in Computing Systems (CHI '13), 2637-2646. https://doi.org/10.1145/2470654.2481365

164. Anon Ymous, Katta Spiel, Os Keyes, Rua M Williams, Judith Good, Eva Hornecker, and Cynthia L Bennett. 2020. "I Am Just Terrified of My Future" - Epistemic Violence in Disability Related Technology Research. In Extended Abstracts of the 2020 CHI Conference on Human Factors in Computing Systems (CHI EA '20), 1-16. https://doi.org/10.1145/3334480.3381828

165. Xiaoyi Zhang, Harish Kulkarni, and Meredith Ringel Morris. 2017. Smartphone-Based Gaze Gesture Communication for People with Motor Disabilities. In Proceedings of the 2017 CHI Conference on Human Factors in Computing Systems (CHI '17), 2878-2889. https://doi.org/10.1145/3025453.3025790

166. Hui Zheng and Vivian Genaro Motti. 2018. Assisting Students with Intellectual and Developmental Disabilities in Inclusive Education with Smartwatches. In Proceedings of the $2018 \mathrm{CHI}$ Conference on Human Factors in Computing Systems (CHI '18), 1-12. https://doi.org/10.1145/3173574.3173924

167. Wei Zhu, Boyd Anderson, Shenggao Zhu, and Ye Wang. 2016. A Computer Vision-Based System for Stride Length Estimation using a Mobile Phone Camera. In Proceedings of the 18th International ACM SIGACCESS Conference on Computers and Accessibility (ASSETS '16), 121-130. https://doi.org/10.1145/2982142.2982156

168. Hong Zou and Jutta Treviranus. 2015. ChartMaster: A Tool for Interacting with Stock Market Charts using a Screen Reader. In Proceedings of the 17th International ACM SIGACCESS Conference on Computers \& Accessibility (ASSETS '15), 107-116. https://doi.org/10.1145/2700648.2809862

169. 2018. Content Analysis. Sage Publishing. Retrieved from https://us.sagepub.com/en-us/nam/contentanalysis/book258450

170. Weaving CHI - Top Keyword Topics. Tableau Software. Retrieved May 13, 2020 from https://public.tableau.com/views/WeavingCHI-

TopKeywordTopics/TopKeywordTopics?:embed=y\&:display_count=yes\&publish=yes:showVizHome=no 